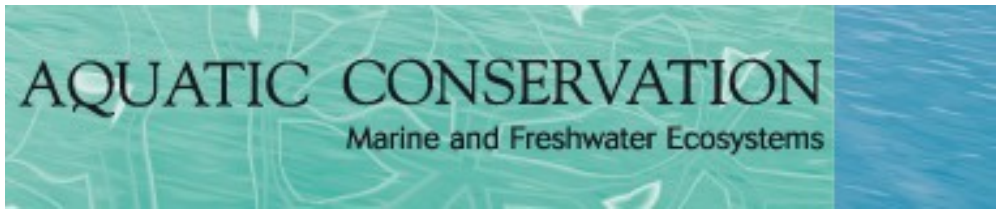

\title{
Fine-scale population structure and connectivity of bottlenose dolphins, Tursiops truncatus, in European waters and implications for conservation
}

\begin{tabular}{|c|c|}
\hline Journal: & Aquatic Conservation: Marine and Freshwater Ecosystems \\
\hline Manuscript ID & AQC-18-0314.R1 \\
\hline Wiley - Manuscript type: & Supplement Article \\
\hline $\begin{array}{r}\text { Date Submitted by the } \\
\text { Author: }\end{array}$ & $\mathrm{n} / \mathrm{a}$ \\
\hline Complete List of Authors: & $\begin{array}{l}\text { Louis, Marie; Scottish Oceans Institute; Sea Mammal Research Unit; } \\
\text { Centre d'Etudes Biologiques de Chize } \\
\text { Nykänen, Milaja; University College Cork School of Biological Earth and } \\
\text { Environmental Sciences } \\
\text { Dillane, Eileen; University College Cork School of Biological Earth and } \\
\text { Environmental Sciences } \\
\text { Alfonsi, Eric; Océanopolis; BioGeMME, UFR Sciences et Techniques, } \\
\text { Université de Brest } \\
\text { Berrow, Simon; Galway-Mayo Institute of Technology, Department of } \\
\text { Life \& Physical Sciences Galway, IE; Irish Whale and Dolphin Group } \\
\text { O'Brien, Joanne; Galway-Mayo Institute of Technology, Department of } \\
\text { Life \& Physical Sciences } \\
\text { Brownlow, Andrew; SAC Wildlife Unit } \\
\text { Covelo, Pablo; CEMMA (Coordinadora para o Estudo dos Mamíferos } \\
\text { Mariños) } \\
\text { Dabin, Willy; Observatoire PELAGIS, UMS 3462 CNRS/Université La } \\
\text { Rochelle } \\
\text { Deaville, Rob; Institute of Zoology, Zoological Society of London } \\
\text { de Stephanis, Renaud; CIRCE, Conservation, Information and Research } \\
\text { on Cetaceans; Department of Conservation Biology, Estación Biológica } \\
\text { de Doñana (CSIC) } \\
\text { Gally, François; GECC (Groupe d'Etude des Cétacés du Cotentin), } \\
\text { Gauffier, Pauline; e) CIRCE (Conservation, Information and Research on } \\
\text { Cetaceans), Cabeza de Manzaneda 3, Pelayo, 11390 } \\
\text { Ingram, Simon; University of plymouth, School of Marine Science and } \\
\text { Engineering } \\
\text { Lucas, Tamara; LIENSs (Littoral Environnement et Sociétés), UMR 7266 } \\
\text { CNRS/Université de La Rochelle } \\
\text { Mirimin, Luca; Galway-Mayo Institute of Technology, Department of Life } \\
\text { \& Physical Sciences Galway, IE } \\
\text { Penrose, Rod; Marine Environmental Monitoring } \\
\text { Rogan, Emer; University of Cork, Zoology, Ecology adn Plant Science } \\
\text { Silva, Monica; Center of the Institute of Marine Research (IMAR) \& } \\
\text { Department of Oceanography and Fisheries, University of the Azores; } \\
\text { Laboratory of Robotics and Systems in Engineering and Science } \\
\text { (LARSyS); Biology Department, Woods Hole Oceanographic Institution } \\
\text { Simon-Bouhet, Benoit; Centre d'Etudes Biologiques de Chize }\end{array}$ \\
\hline
\end{tabular}




\section{SCHOLARONE $^{\text {TM }}$
Manuscripts \\ SCHOLARONE
Manuscripts}

\begin{tabular}{|r|l|}
\hline & Gaggiotti, Oscar; Scottish Oceans Institute \\
\hline $\begin{array}{r}\text { Broad habitat type } \\
\text { (mandatory) select 1-2: }\end{array}$ & coastal < Broad habitat type, ocean < Broad habitat type \\
\hline $\begin{array}{r}\text { General theme or application } \\
\text { (mandatory) select 1-2: }\end{array}$ & $\begin{array}{r}\text { genetics < General theme or application, Special Area of Conservation < } \\
\text { General theme or application }\end{array}$ \\
\hline $\begin{array}{r}\text { Broad taxonomic group or } \\
\text { category (mandatory, if }\end{array}$ & mammals < Broad taxonomic group or category \\
relevant to paper) select 1-2: & \\
\hline $\begin{array}{r}\text { Impact category (mandatory, } \\
\text { if relevant to paper) select 1- } \\
2:\end{array}$ & \\
\hline
\end{tabular}




\section{Fine-scale population structure and connectivity of bottlenose}

2 dolphins, Tursiops truncatus, in European waters and implications

3 for conservation

4 Milaja Nykänen ${ }^{1 *}$, Marie Louis ${ }^{2,3,4 *}$, Eileen Dillane ${ }^{1}$, Eric Alfonsi ${ }^{5,6}$, Simon

5 Berrow $^{7,8}$, Joanne O’Brien ${ }^{7,8}$, Andrew Brownlow ${ }^{9}$, Pablo Covelo ${ }^{10}$, Willy Dabin ${ }^{11}$,

6 Rob Deaville ${ }^{12}$, Renaud de Stephanis ${ }^{13,14}$, François Gally ${ }^{15}$, Pauline Gauffier ${ }^{14}$,

7 Simon N. Ingram ${ }^{16}$, Tamara Lucas ${ }^{17}$, Luca Mirimin ${ }^{8}$, Rod Penrose ${ }^{18}$, Emer Rogan ${ }^{1}$,

8 Mónica A. Silva ${ }^{19,20,21}$, Benoit Simon-Bouhet ${ }^{4}$, Oscar E. Gaggiotti ${ }^{2}$

9

$10 *$ these authors contributed equally

11 Correspondence: Milaja Nykänen: milaja.ny@gmail.com - Marie Louis:

12 marielouis17@hotmail.com

14 (1) School of Biological, Earth and Environmental Sciences, University College

15 Cork, North Mall, Cork, Ireland

16 (2) Scottish Oceans Institute, Gatty Marine Laboratory, East Sands, St Andrews

17 KY16 8LB, Scotland, UK

18 (3) Sea Mammal Research Unit, Scottish Oceans Institute, University of St Andrews,

19 Gatty Marine Laboratory, East Sands, St Andrews KY16 8LB, Scotland, UK

20 (4) Centre d'Etudes Biologiques de Chizé, UMR 7372, Université de La Rochelle,

21 France.

22 (5) Océanopolis, Brest, France.

23 (6) BioGeMME, UFR Sciences et Techniques, Université de Brest, France.

24 (7) Irish Whale and Dolphin Group, Kilrush, Co Clare, Ireland.

25 (8) Marine and Freshwater Research Centre, Department of Natural Sciences,

26 School of Science and Computing, Galway-Mayo Institute of Technology, Dublin

27 Road, H91 T8NW Galway, Ireland,

28 (9) SAC Wildlife Unit, Inverness, Scotland.

29 (10) CEMMA (Coordinadora para o Estudo dos Mamiferos Mariños), Gondomar,

30 Spain. 
31 (11) Observatoire PELAGIS, UMS 3462 CNRS/Université La Rochelle, France.

32 (12) Institute of Zoology, Zoological Society of London, England.

33 (13) Department of Conservation Biology, Estación Biológica de Doñana (CSIC),

34 Sevilla, Spain.

35 (14) CIRCE (Conservation, Information and Research on Cetaceans), Pelayo, Spain.

36 (15) GECC (Groupe d'Etude des Cétacés du Cotentin), Cherbourg-Octeville,

37 France.

38 (16) School of Marine Science and Engineering, Plymouth University, Plymouth PL4

$398 A A, U K$,

40 (17) LIENSs (Littoral Environnement et Sociétés), UMR 7266 CNRS/Université de

41 La Rochelle, France.

42 (18) Marine Environmental Monitoring, Cardigan, Wales, United Kingdom.

43 (19) Center of the Institute of Marine Research (IMAR) \& Department of

44 Oceanography and Fisheries, University of the Azores, Horta, Azores, Portugal.

45 (20) Laboratory of Robotics and Systems in Engineering and Science (LARSyS),

46 Lisboa, Portugal.

47 (21) Biology Department, Woods Hole Oceanographic Institution, Woods Hole,

48 Massachusetts, United States of America.

49

\section{Abstract}

51 1. Protecting species often involves the designation of protected areas, wherein

52 suitable management strategies are applied either at the taxon or ecosystem level.

53 Special Areas of Conservation (SACs) have been created in European waters under

54 the Habitats Directive to protect bottlenose dolphins, Tursiops truncatus, which

55 forms two ecotypes, pelagic and coastal.

56 2. The SACs have been designated in coastal waters based on photo-identification

57 studies that have indicated that bottlenose dolphins have relatively high site fidelity.

58 However, individuals can carry out long-distance movements which suggest

59 potential for demographic connectivity between the SACs as well as with other areas. 
60 3. Connectivity can be studied using genetic markers. Previous studies on the species

61 in this area used different sets of genetic markers and therefore inference on the fine-

62 scale population structure and demographic connectivity has not yet been made at a

63 large scale. A common set of microsatellite markers was used in this study to provide

64 the first comprehensive estimate of genetic structure of bottlenose dolphins in

65 European Atlantic waters.

66 4. As in previous studies, a high level of genetic differentiation was found between

67 coastal and pelagic populations. Genetic structure was defined at an unprecedented

68 fine-scale level for coastal dolphins leading to identification of five distinct coastal

69 populations inhabiting the following areas: Shannon estuary, west coast of Ireland,

70 English Channel, coastal Galicia, east coast of Scotland, and Wales/West Scotland.

71 Demographic connectivity was very low among most populations with less than $10 \%$

72 migration rate suggesting no demographic coupling among them. Each local

73 population should therefore be monitored separately.

74 Keywords: coastal, ocean, population genetics, Special Area of Conservation,

75 mammals, bottlenose dolphins 


\section{Introduction}

78 Protecting species and their habitats is the goal of conservation biology, and this often

79 includes the designation of protected areas, wherein suitable management strategies

80 are applied either at the taxon or ecosystem level. According to the definition by the

81 World Conservation Union (IUCN), a Marine Protected Area (MPA) is "any area of

82 intertidal or subtidal terrain, together with its overlying water and associated flora,

83 fauna, historical and cultural features, which has been reserved by law or other

84 effective means to protect part or all of the enclosed environment" (Kelleher \&

85 Phillips, 1999, 18). The usefulness of static MPAs to preserve biodiversity or to protect

86 a particular species or population has been debated (e..g._._Agardy,_di_S

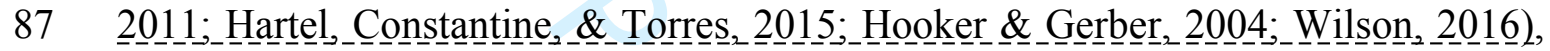

88 but they remain the primary spatial conservation unit worldwide and are key

89 components of various conservation plans (e.g., the United Nations Plan for

90 Biodiversity (2011-2020), the IUCN Worlds Parks Congress and the European

91 Biodiversity Strategy to 2020 (European Commission, 2011)). In European waters, the

92 Member States of the European Union are required to designate Special Areas of

93 Conservation (SACs) for species listed in Annex II of the Habitats Directive (European

94 Economic Community, 1992), which includes two cetacean species; the harbour

95 porpoise, Phocoena phocoena, and the common bottlenose dolphin, Tursiops

96 truncatus. These SACs, which are part of the European Natura 2000 strategy, should

97 represent areas essential for the species' life and reproduction. In addition to the

98 protection under the Habitats Directive, as top predators, bottlenose dolphins are

99 considered as one of the indicator species for 'good environmental status' (GES) in

100 coastal waters by the Marine Strategy Framework Directive (MSFD, Council of the

101 European Communities, 2008). The aim of MSFD is to protect the European marine 
102 environment by applying a comprehensive ecosystem-based approach to the

103 management of human activities, and by maintaining or restoring the favourable

104 conservation status of a number of species.

105 Previous research using photo-identification has shown that most coastal bottlenose

106 dolphin populations in Europe comprise between 30 and 400 resident individuals with

107 strong site fidelity to their respective coastal site (e.g., Cheney et al., 2013; Ingram \&

108 Rogan, 2002; Louis et al., 2015). However, also based on photo-identification studies,

109 some of these individuals are highly mobile travelling distances of hundreds of

110 kilometres around the UK and Ireland (Cheney et al., 2013; Ingram, Englund, \&

111 Rogan, 2001; Ingram \& Rogan, 2003; O’Brien et al., 2009; Robinson et al., 2012).

112 Nonetheless, the high site-fidelity and the preferential use of some geographical areas

113 indicate that coastal bottlenose dolphins may be very sensitive to changes in local

114 environmental conditions, ecological factors, or anthropogenic disturbance. The

115 sensitivity of bottlenose dolphins to these threats is exacerbated by their position as an

116 apex predator and also by their low reproductive rates (Connor, Wells, Mann, \& Read,

117 2000; Quick et al., 2014). The main threats in coastal environments include pollutants

118 such as xenobiotic chemicals (Jepson et al., 2016; Reif, Schaefer, Bossart, \& Fair,

119 2017), reduced prey availability, habitat degradation, disturbance from vessel traffic

120 (Lusseau, Bain, Williams, \& Smith, 2009; Pirotta, Merchant, Thompson, Barton, \&

121 Lusseau, 2015; Williams, Bain, Smith, \& Lusseau, 2009), entanglement and incidental

122 bycatch, direct hunting, marine construction and anthropogenic noise (Hammond et

123 al., 2012; Meissner et al., 2015; Pirotta et al., 2015). The increased risks of

124 demographic perturbation of dolphin populations due to human activities highlights

125 the need for the design and management of protected areas ensuring that dolphin 
126 habitat remains favourable and does not deteriorate. A careful investigation of the

127 population structure and quantification of the genetic and demographic connectivity is

128 also necessary as small isolated populations may require more protection due to their

129 reduced genetic resilience.

130 An important step towards the conservation of bottlenose dolphins was taken under

131 the Habitats Directive by designating SACs across the European North-east Atlantic

132 and Mediterranean coastal waters. These designations were based on photo-

133 identification and habitat use surveys showing long-term site-fidelity (Anon, 2012).

134 Another important step towards their conservation is to evaluate population structure

135 and connectivity of populations between the protected areas as well as with other areas.

136 This is particularly important because of the propensity for some individuals to carry

137 out long-distance movements, which suggests potential demographic connectivity

138 between the populations. It is unclear if such movements can result in migration rates

139 that could lead to correlated population dynamics. There is a paucity of studies

140 assessing the level of migration that will lead to demographic coupling (Waples \&

141 Gaggiotti, 2006); a process by which changes in population size in one population are

142 influenced by changes taking place in another population (Hastings, 1993). However,

143 a simulation study by Hastings (1993) indicated that under a simple two-population

144 density-dependent model, a migration rate of $10 \%$ or more can lead to coupled

145 dynamics, which would require monitoring the populations as a single

146 management/conservation unit. Thus, a threshold of $10 \%$ migration above which two

147 local populations are considered independent management units can be used as an

148 operational criterion to address conservation problems.

149 The most cost-effective approach to evaluate demographic connectivity and fine-scale 
150 population subdivision is based on the use of genetic markers and population genetics 151 principles. Thus, a recent workshop on bottlenose dolphin conservation (December 152 2016; Ó Cadhla \& Marnell, 2017) concluded that one of the main priorities for 153 implementing the afore-mentioned EU directives for this species was a fine-scale 154 population genetics analysis of dolphins inhabiting European waters. This will allow 155 the definition of meaningful management units (MUs), which is essential when setting 156 up strategies for conservation and monitoring, including the estimation of population 157 trends and the evaluation of the impacts of anthropogenic activities. Note that in the 158 past, MUs were frequently defined in genetic terms as genetic management units 159 (GMUs), following Moritz (1994, 374): "populations with significant divergence of 160 allele frequencies at nuclear or mitochondrial loci, regardless of the phylogenetic 161 distinctiveness of the alleles". However, it is now accepted that MUs comprise 162 demographically independent populations, thus estimating migration rates forms a 163 central part of the assessment of suitable MUs (Allendorf, Luikart, \& Aitken, 2013; 164 Palsbøll, Berube, \& Allendorf, 2007). Furthermore, the criterion underlying GMUs is 165 not entirely appropriate from a demographic point of view because migration rates $(\mathrm{m})$ 166 well below $10 \%$ can still lead to an absence of significant allelic differentiation (e.g., 167 if local population size is $100, m>0.01$ will lead to absence of genetic differentiation; 168 c.f. Waples \& Gaggiotti, 2006). Nevertheless, population genetics principles can be 169 used to estimate migration rates to implement the $10 \%$ migration threshold criterion. 170 In addition, other measures can be used in order to define MUs, such as ecological 171 tracers (e.g.g_Giménez et_al_._2018) or analyses of population viability (Olsen et al., 172 2014). 
173 Previous genetic studies on bottlenose dolphins worldwide have identified a clear 174 population structuring based on nuclear microsatellites and mitochondrial markers 175 with varying geographical scales (e.g._._Allen_ent_al._._2016; 176 1998; Rosel, Hansen _ \&_Hohn, 2009; V_ollmer__ \&_Rosel_2017). The same has been 177 found in European waters (Gaspari et al., 2015; Louis, Viricel et al., 2014; Mirimin et 178 al., 2011; Natoli, Peddemors, \& Hoelzel, 2003; Nichols et al., 2007; Nykänen et al., 179 2018; Quérouil et al., 2007), and in some areas this structuring is present even between 180 geographically adjacent populations (e.g., between the Shannon estuary and the rest of 181 the west coast of Ireland, Mirimin et al., 2011; Nykänen et al., 2018). Recently, Louis, 182 Viricel et al. (2014) determined that coastal and pelagic bottlenose dolphins in 183 European waters were genetically and ecologically distinct from each other and that 184 further structuring within the two ecotypes existed; the coastal ecotype was divided 185 into the Coastal South population, which included individuals from Normandy and 186 Galicia, and the Coastal North population, consisting of coastal bottlenose dolphins 187 around the UK and Ireland. However, these authors did not have sufficient sample 188 sizes from each local coastal population to fully investigate fine-scale structuring and 189 no samples were available from the population occupying the Shannon Estuary in 190 Ireland. Therefore, it remained unclear whether further fine-scale population structure 191 in coastal waters exists and whether the movement of mobile individuals maintains 192 connectivity between the local populations. Furthermore, the previous studies on 193 bottlenose dolphin population structure (Fernandez et al., 2011; Louis, Viricel et al., 194 2014; Mirimin et al., 2011; Natoli et al., 2003; Nykänen et al., 2018) have all employed 195 different sets of microsatellite markers, preventing the comparison between studies, 196 and thus giving a fragmented vision of population structure. The purpose of this study, 197 therefore, was to evaluate the population structure of bottlenose dolphins in European 
198 Atlantic waters at a fine-scale level, including samples from the Shannon Estuary and

199 a larger number of samples from west of Ireland and using a common set of 200 microsatellite markers between the studies by Louis, Viricel et al. (2014), Mirimin et 201 al. (2011) and Nykänen et al. (2018). The demographic dispersal between the 202 populations was estimated, and the findings are discussed in light of the conservation 203 of the species in European waters.

\section{Materials and methods}

205 Ninety-six samples from Nykänen et al. (2018), were genotyped at 14 microsatellites 206 loci used in Louis, Viricel et al. (2014) (Tut02, Ttr34, Ttr58, Ttr04, Ttr63, Tut01, 207 Ttr19, Tut05, TtrFF6, Tut09, Ttr11, Ttr48, EV37, TexVet7, see characteristics and 208 amplification conditions in Table S1 and Supplementary text S2 of Louis, Viricel et 209 al. (2014). This dataset included 13 samples from Louis, Viricel et al. (2014) which 210 were known to be duplicates based on their sample ID. Additionally, three samples 211 previously genotyped in Louis, Viricel et al. (2014) were used as a scale, or controls, 212 to define allele size. Nine samples from Corsica from Louis, Viricel et al. (2014) were 213 excluded from this study as they are out of the area of interest. Further two samples 214 from Louis, Viricel et al. (2014) and two samples from Nykänen et al. (2018), were 215 excluded as they had less than eight loci genotyped out of 14 loci. The overall dataset 216 used in the present study thus consists of 425 individuals; 344 samples from Louis, 217 Viricel et al. (2014) and 81 samples (excluding the 13 duplicate samples) from 218 Nykänen et al. (2018), with the latter originating mainly from the Shannon and West 219 Ireland populations. The 425 samples include 228 biopsy samples and 197 samples 220 from stranded animals. 
221 The biopsy samples were taken in coastal Normandy (English Channel, France,

$222 \mathrm{~N}=90$ ), West Ireland (Connemara-Mayo-Donegal area, N=30), Cork harbour (Ireland,

$223 \mathrm{~N}=4$ ) and Shannon Estuary (Ireland, N=45), offshore Ireland (on the shelf edge, see

224 Figure 1, N=1), the Azores (Portugal, N=19), Gibraltar and Cadiz (Spain, N=39).

225 Fifteen samples of stranded dolphins were matches to photo-identification catalogues

226 of coastal animals from East Scotland $(\mathrm{N}=10)$, Normandy $(\mathrm{N}=2)$, and the Arcachon

227 estuary (Bay of Biscay, France, $\mathrm{N}=3$ ). The rest of the stranded animals came from

228 Ireland $(\mathrm{N}=31)$, Wales $(\mathrm{N}=26)$, Scotland $(\mathrm{N}=34)$, France $(\mathrm{N}=58)$ and Spain $(\mathrm{N}=33)$.

229 The coastal or pelagic origin of all stranded animals was identified using genetic

230 assignments to the same cluster as biopsied individuals (Louis, Viricel et al., 2014).

231 Ecotype assignment was further confirmed for some of the individuals using photo-

232 identification catalogues of known coastal animals as detailed above $(\mathrm{N}=15)$, stable

233 isotopes $(\mathrm{N}=40$, Louis, Fontaine et al., 2014) and/or drift prediction models $(\mathrm{N}=66$ 6,

234 Louis, Viricel et al., 2014). For example, all samples of stranded animals from East

235 Scotland were predicted to have died close to shore (Louis, Viricel et al., 2014).

236 Individuals stranded in the English Channel in France were predicted to originate from

237 coastal waters while individuals stranded in the Bay of Biscay were predicted to come

238 both from the shelf and the shelf-edge (Louis, Viricel et al., 2014).

239 Microsatellite marker quality

240 The 13 identified duplicate samples between the two studies were used to calculate

241 genotyping error rate by dividing the number of inconsistent genotypes among the

242 duplicates (three) by the total number of genotypes (364 minus six missing genotypes,

243 therefore 358). 
244 All individuals were successfully amplified for at least eight loci and there was $1.80 \%$

245 of missing values in the dataset. Microchecker 2.2.3 was used to check for null alleles

246 and scoring errors (Van Oosterhout, Hutchinson, Wills, \& Shipley, 2004). Departures

247 from Hardy-Weinberg equilibrium (HWE) and linkage equilibrium were tested using

24810000 dememorizations, 1000 batches and 10000 iterations per batch in GENEPOP

249 on the web version 4.2 (Raymond \& Rousset, 1995; Rousset, 2008). Tests were

250 conducted for the whole dataset and for the finest level of population structure

251 identified by the clustering methods (see below).

\section{Genetic population structure}

253 Population delimitation and assignment of individuals was done using three genetic

254 clustering methods, which were applied to: (i) the full microsatellite dataset $(\mathrm{N}=425)$,

255 and (ii) a subset comprising only coastal individuals $(\mathrm{N}=269)$. The clustering methods

256 include: two Bayesian methods implemented in STRUCTURE (Pritchard, Stephens,

257 \& Donnelly, 2000) and TESS (Durand, Chen, \& Francois, 2009) and a multivariate

258 method, Discriminant Analysis of Principal Components (DAPC) (Jombart, Devillard,

$259 \&$ Balloux, 2010). TESS was also run considering only the pelagic individuals

260 (N=156). For the coastal dolphins, if any cluster included several sampling locations,

261 TESS was re-run considering only those sampling areas to determine if there was

262 further genetic structuring among them.

263 The three different approaches were used to ensure the robustness of the inferred

264 results, as determining the most likely number of clusters can be challenging (Guillot,

265 Leblois, Coulon, \& Frantz, 2009). STRUCTURE assigns individuals to clusters by

266 minimizing HWE and linkage disequilibria (Pritchard et al., 2000). TESS implements

267 a probabilistic model similar to STRUCTURE but is spatially explicit as it incorporates 
268 the geographic coordinates of the sampled individuals as a priori information (Durand

269 et al., 2009). In contrast to these two Bayesian approaches that use the full data, DAPC

270 uses genetic similarity to cluster individuals and does not make any population genetic

271 model assumptions, i.e., it does not assume clusters are in HWE (Jombart et al., 2010).

272 TESS was run using the conditional auto-regressive (CAR) admixture model with a

273 burn-in of 20000 steps followed by 120000 Markov Chain Monte Carlo (MCMC)

274 steps. The number of clusters $(K)$ tested varied between two and ten when considering

275 the whole data set and the coastal samples only, and between two and six when

276 analysing the pelagic samples only. In these cases, ten replicate runs for each value of

$277 K$ were performed but six replicates were used in the analyses that excluded closely

278 related individuals. The spatial interaction parameter was left at the default value (0.6)

279 with a linear degree trend. To select the most likely number of clusters, the Deviance

280 Information Criterion (DIC) values were plotted against $K$ and plots of individual

281 membership proportions were examined. Consistency across runs was also checked.

282 STRUCTURE was run using the admixture models with correlated and independent

283 allele frequencies, without a priori information. Ten independent runs for number of

284 clusters ranging from one to ten were carried out with a burn-in of 100000 iterations

285 followed by 500000 MCMC steps. Convergence of each run was confirmed visually

286 by inspecting the $\alpha$-parameter and likelihood chains, and the consistency across runs

287 was examined using pophelper (Francis, 2017), a package that implements the

288 functions from software CLUMPP (Jakobsson \& Rosenberg, 2007) in R (R Core

289 Team, 2018). If the results between replicate runs differed (a sign of MCMC non-

290 convergence across all runs), STRUCTURE was re-run increasing the number of

291 MCMC steps to 500000 burn-in followed by 1000000 samples. To determine the 
292 most likely $K$, the likelihood $(\mathrm{L}(K))$, the rate of change in the likelihood $\left(\mathrm{L}^{\prime}(K)\right.$ and

$293 \mathrm{~L}, '(K))$ and $\Delta K$ (Evanno, Regnaut, \& Goudet, 2005) were calculated and plotted for

294 each $K$ using pophelper (Francis, 2017), and individual membership proportion plots

295 for the run with the highest likelihood were plotted for the most likely values of $K$,

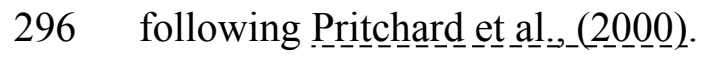

297 The DAPC analysis was performed using the package adegenet 2.1.1 (Jombart, 2008)

298 in $\mathrm{R}$ following the recommendations in Jombart_(2012). The most likely number of

299 clusters was determined with the $K$-means method using the decrease in Bayesian

300 Information Criterion (BIC) value and, in the absence of an "elbow" (a clear drop

301 followed by a sharp increase) in the BIC curve, by plotting and inspecting the

302 membership proportions for the values of $K$ with the lowest BIC values. Maximum

303 number of clusters tested was set to ten, and the linear discriminant analysis was

304 performed on $80 \%$ of the retained principal components. Scatter-plots were produced

305 for varying $K$. The membership proportion plots were checked for concordance with

306 the number of estimated clusters and whether membership proportions to those clusters

307 were high $(>80 \%)$.

308 Results of analyses characterizing population structure presented in the main text are

309 based on TESS because they were the most consistent between runs, and importantly,

310 were more concordant with photo-identification studies (see details in the Results

311 section) than those of the two other genetic clustering methods.

312 The inclusion of closely related individuals can affect population structure analyses

313 (Anderson \& Dunham, 2008). Therefore the Queller and Goodnight's (Queller \&

314 Goodnight, 1989) relatedness coefficient $(R)$ was estimated among individuals using

315 COANCESTRY (Wang, 2011) within each population identified by TESS. TESS was 
316 re-run after removing one individual from each pair of individuals showing a

317 relatedness coefficient larger or equal to 0.45 as in Rosel et al. (2009).

$318 \quad$ Nuclear genetic differentiation and diversity

319 Genetic differentiation, i.e., pairwise $F_{\mathrm{ST}}$ (Weir \& Cockerham, 1984) and Jost's $D$

320 (Jost, 2008), between the populations inferred by TESS, were estimated using the R-

321 package diveRsity (Keenan, McGinnity, Cross, Crozier, \& Prodöhl, 2013). The level

322 of significance was assessed using 1000 bootstrap samples. For each population, the

323 mean number of alleles (NA), allelic richness (AR), inbreeding coefficient $\left(F_{\text {IS }}\right)$,

324 observed heterozygosity $(\mathrm{Ho})$ and expected heterozygosity $(\mathrm{He})$, were calculated, also

325 in diveRsity. Program CONVERT (Glaubitz, 2004) was used to count private alleles.

326 Diversity indices were also calculated separately for each locus.

\section{Recent migration rates}

328 Recent migration rates (i.e., within the last two generations) between the populations

329 identified by TESS at the finest level of genetic structuring were estimated using

330 BayesAss (Wilson \& Rannala, 2003). Following Rannala (2013), preliminary runs

331 were first performed to tune up MCMC parameters ensuring proposal acceptance rates

332 around $30 \%$. Ten runs were performed with a burn-in of $1 \times 10^{6}$ iterations followed by

$3332 \times 10^{7}$ MCMC iterations and a sampling frequency of 1000 . Trace files were plotted

334 using Tracer (Rambaut \& Drummond, 2007) to check for convergence and mixing.

335 Consistency of the results between the runs was also checked. 


\section{Results}

338 The genotyping error rate between the two datasets was 0.0084. Significant departures

339 from Hardy-Weinberg equilibrium (HWE) were detected for loci EV37 and Ttr34 in

340 one population each (Appendix S1). As deviation was significant in only one out of

341 seven populations for each locus, these loci were kept in the analyses. Linkage

342 disequilibrium was not significant for any of the pairwise comparisons within each

343 population. No null alleles or scoring errors were found.

\section{Individual assignment methods}

345 The most likely number of clusters when running TESS on the whole dataset was six.

346 The delimitation of the six clusters (see Figure 2, Appendices S2a and S2b) and the

347 whole data set (i.e., including both coastal and pelagic individuals) is as follows. The

348 first cluster was mainly composed of coastal dolphins from East Scotland (ten of which

349 were identified as resident based on photo-identification catalogue), Wales and a few

350 individuals from West Scotland and Galicia. The second cluster consisted of

351 individuals biopsy sampled in the Connemara-Mayo-Donegal area on the west coast

352 of Ireland (i.e., the West Ireland population). The third cluster included coastal

353 biopsies from the Shannon Estuary and four biopsy samples from dolphins sampled in

354 Cork harbour, Ireland (i.e., the Shannon population). The fourth cluster was composed

355 of coastal dolphins sampled in the English Channel, in particular in the Gulf of Saint-

356 Malo, three stranded dolphins previously photo-identified as part of a small group that

357 used to reside in the Arcachon estuary (Bay of Biscay, France) and a few individuals

358 from Galicia (i.e., the English Channel population). The fifth cluster included stranded

359 samples from the west coasts of the United Kingdom, Ireland, France and northern

360 Spain, and biopsy samples from the Northeast Atlantic and around the Azores (i.e. the 
361 Pelagic Atlantic population). The last cluster was composed of individuals sampled in

362 the Strait of Gibraltar and the Gulf of Cadiz (i.e., the Gibraltar-Cadiz population).

363 When considering $K=2$, populations (e) and (f) (in Figure 2), were grouped together in

364 one cluster and all remaining populations in the other (TESS, results not shown). This

365 result highlights the hierarchical structuring of the species into coastal (populations (a)

366 to (d)) and pelagic (populations (e) and (f)). Indeed, populations (e) and (f) consist of

367 biopsies from individuals sampled in deep waters of the Azores, North Atlantic and

368 Strait of Gibraltar (plus some samples from the Gulf of Cadiz) as well as samples from

369 stranded animals from the West coasts of Scotland, Ireland, France and Spain.

370 In order to study in more detail the structuring among the coastal individuals, TESS

371 was re-run with coastal samples only. In this case, the most likely number of clusters

372 was five (Figure 3A). The DIC plot indicated a plateau at $K=5$ or $K=6$ (Appendix S3a)

373 but examination of membership proportions indicated that there were actually only

374 five clusters in all of the replicate runs with $K=6$ (Figure $3 \mathrm{~A}$, Appendix S3b). Thus,

375 this finer scale analysis uncovered an additional cluster among the coastal dolphins.

376 More precisely, the cluster comprising individuals sampled in Scotland, Wales and

377 Galicia (Figure 2a) was divided into two clusters: one comprising individuals from

378 Scotland and Wales (Figure 3A(a)) and another including individuals from Galicia

379 (i.e., the Galicia population, Figure 3A(e)). All remaining coastal individuals (Figure

$3802 \mathrm{~b}-\mathrm{d}$ ) were clustered as before (see Figure $3 \mathrm{~A}(\mathrm{~b}-\mathrm{d})$ ).

381 To further explore fine-scale structuring, TESS was re-run for only the individuals of

382 the Scotland-Wales cluster (Figure 3A(a)), as this population encompassed several

383 geographical areas. Further population structure was found within this area (see Figure

384 3B and Appendices S4a and S4b) with the first cluster including individuals from 
385 Wales and a few individuals from West Scotland (Wales-West Scotland population,

386 Figure 3B(a)) and a second cluster consisting of individuals from East Scotland (East

387 Scotland population, Figure 3B(b)).

388 When running TESS on the pelagic samples only, no further genetic structuring was

389 found but the best number of clusters was two, corresponding to the Pelagic Atlantic

390 and the Gibraltar-Cadiz populations (Appendices S5a and S5b), inspection of the

391 admixture plots for $K=2$ to $K=6$ also indicated that there were only two clusters, results

392 shown for $K=2$ and $K=3$ in S5b.

393 Additional analyses with STRUCTURE and DAPC provide general support for TESS

394 results but were either less stable due to convergence problems (STRUCTURE) or

395 were not completely congruent with results of photo-identification studies. When all

396 samples $(\mathrm{N}=425)$ were included in STRUCTURE runs, the Evanno-method $(\Delta \mathrm{K}$,

397 Evanno et al., 2005) detected only the uppermost hierarchical structure i.e., the

398 division into coastal and pelagic at $K=2$ (Appendix S9d). Nevertheless, using the $\mathrm{L}(K)$

399 criterion proposed by Pritchard et al. (2000), the most likely $K$ was six (Appendix S9a),

400 in concordance with TESS. Beyond this, no new genetic clusters emerged in the

401 membership proportion plots (Appendix S10). The full description of STRUCTURE

402 results when including all samples and only the coastal samples is given in Appendices

403 S7 and S11, respectively. In contrast to TESS, STRUCTURE could not detect the

404 samples from Galicia as a separate cluster when only coastal samples were included.

405 When all samples were included in the DAPC analyses, the best number of clusters

406 was found at $K=6$ (Appendices S15-S16). The clusters were almost identical to those

407 found with TESS and STRUCTURE, dividing the Irish samples into Shannon and

408 West coast populations and separating the biopsy samples from Cadiz-Gibraltar from 
409 the Azores biopsies and stranded samples thought to be from a pelagic origin.

410 However, in contrast to TESS, DAPC also failed to delineate the samples from Galicia

411 into a separate cluster when only coastal samples were included. The full description

412 of results when including only the coastal samples is given in Appendix S17.

413 As mentioned previously (Methods), the inclusion of closely related individuals can

414 bias results of genetic clustering methods. The presence of related individuals varied

415 among the geographic areas considered in this study. They were almost inexistent

416 among pelagic samples as no closely related individuals (with a relatedness coefficient

417 of $\geq 0.45$ ) were found in the Gibraltar-Cadiz population and only three pairs were found

418 in the pelagic Atlantic population. In contrast, relatedness among coastal individuals

419 varied from $1.15 \%$ in the English Channel population to $5.13 \%$ in the Galicia

420 population. Therefore, TESS was re-run for the coastal populations only taking out

421 one individual from each close kin pair $(\mathrm{N}=79)$. The results were similar to the runs

422 including close relatives and also indicated five clusters corresponding to the Shannon,

423 the West Ireland, the English Channel, the East and West Scotland-Wales and the

424 Galicia populations (Appendices S6a and S6b). As the results with and without 425 including close relatives were similar, we conclude that the results from TESS 426 presented in Figures 2 and 3 are highly reliable and can be used to draw inferences on 427 migration rates.

428 Results from genetic clustering methods such as TESS can be used as a first approach 429 to study migration. More precisely, individuals assigned to a population different from 430 the geographical area where they were sampled can be considered as likely migrants. 431 One individual sampled in Galicia had a high assignment probability to the English 432 Channel population (0.75), another individual sampled in the English Channel was 
433 assigned to the West Ireland population (with 0.86 probability) and a third individual

434 sampled in the Shannon estuary was assigned to the West Ireland population (with

4350.77 probability). These results suggest that there is some connectivity between

436 dolphin populations and further analyses with BayesAss are warranted.

437 Nuclear genetic differentiation and diversity

438 All nuclear $F_{\mathrm{ST}}$ and Jost's D pairwise comparisons between the eight populations

439 identified with TESS were significant. The highest level of differentiation was between 440 pelagic and coastal populations (Table 1). When considering $F_{\mathrm{ST}}$, the lowest level of

441 differentiation was detected between the two pelagic populations. In terms of Jost's $D$

442 the lowest differentiation was between Wales and East Scotland. The Shannon

443 population was the most differentiated from the pelagic populations followed by the

444 West Ireland population for both indices.

445 Nuclear genetic diversity (Allele Richness (AR) and Observed Heterozygosity $(\mathrm{Ho})$ )

446 was significantly lower in most coastal populations than in the pelagic populations,

447 with Kruskal-Wallis $P<0.01$ in all AR coastal-pelagic comparisons except between

448 English Channel and Gibraltar-Cadiz $(P=0.07)$, and $P<0.05$ in all Ho comparisons

449 except between Gibraltar-Cadiz and English Channel $(P=0.12)$, Gibraltar-Cadiz and

450 Galicia $(P=0.18)$ and Pelagic Atlantic and Galicia $(P=0.09)$ (Table 2, Appendix S20

451 for values per loci per populations). Among the coastal populations, allele richness

452 was highest in the English Channel population and lowest in the Shannon population,

453 between which the difference was significant (Kruskal-Wallis $P<0.05$ ). The highest

454 number of private alleles was found in the pelagic Atlantic population $(\mathrm{N}=26)$, two

455 private alleles were found in the Gibraltar/Cadiz and the English Channel populations

456 and one private allele in the East Scotland and in the West Scotland-Wales 
457 populations. A significant heterozygote deficiency was detected in the Shannon, West

458 Ireland and Galicia populations (Table 2).

\section{Recent migration rates}

460 Estimates of recent migration rates were highly consistent between runs; therefore, the 461 results presented here are based on a randomly chosen run (Table 3). Estimated 462 migration rates were very low between most populations, around $<1 \%$ per generation, 463 with an upper bound for the $95 \%$ credibility interval of less than $10 \%$ and a lower 464 bound of 0 (Table 3 ). The only exceptions were mean migration rate of $18.1 \%$ between 465 Galicia and East Scotland, and mean rate of 25.7\% from East Scotland to Wales-West

466 Scotland. However, these higher migration rates need to be interpreted with caution as 467 individuals from Scotland, Wales and Galicia consisted of stranded animals. As 468 mentioned before, although a portion of the East Scotland individuals were matched 469 to photo-identification catalogues of known coastal animals, there is uncertainty about 470 the origin of strandings in Wales and West Scotland.

\section{Discussion}

473 This study presents, to date, the most comprehensive analysis of the genetic structure

474 of bottlenose dolphins in the North-east Atlantic as it includes samples collected from

475 an unprecedentedly wide geographical area, which unlike previous studies, were 476 analysed using a common set of microsatellite markers. The results of this study, 477 therefore, have the potential to be used to identify management units in this area and 478 thus offer a significant contribution to the conservation of the species in European 479 waters. 
480 A first level of genetic differentiation was found between coastal and pelagic 481 populations, as in a previous study (Louis, Viricel et al., 2014). The results from TESS

482 in terms of assignments to coastal and pelagic ecotypes were identical to that of Louis, 483 Viricel et al. (2014) with only one exception. One individual that stranded in the Bay 484 of Biscay which belonged to the Pelagic Mediterranean population in Louis, Viricel et 485 al. (2014) clustered with the coastal English Channel population in this study. No 486 further genetic structure was found within the two pelagic populations (i.e., Pelagic 487 Atlantic and Gibraltar-Cadiz).

488 Fine-scale population structure among coastal bottlenose dolphins from different 489 geographical locations corresponded to the different local populations that inhabit the 490 Shannon estuary, west of Ireland, the English Channel, Galicia, East Scotland, and 491 Wales/West Scotland. Previous studies only identified large-scale population structure 492 in coastal waters due to uneven sampling of each local coastal population (Louis, 493 Viricel et al., 2014) or fine-scale population structure in small geographic regions 494 (Fernandez et al., 2011; Mirimin et al., 2011, Nykänen et al., 2018). Thus, the results 495 of this study highlight the need for and the power of broad scale collaboration when 496 working on the conservation of highly mobile species that can move across national 497 borders. The level of resolution was only possible thanks to broad international 498 collaborations, sample sharing and careful calibration of allele scoring to overcome 499 the difficulties of comparing genotypes across studies.

500 Although results of all three genetic clustering methods were generally consistent, their 501 comparison with independent results from photo-identification studies highlighted 502 differences in performance among them. More explicitly, the coastal population 503 assignments inferred with TESS were concordant with photo-identification studies 
504 indicating geographically isolated populations with site fidelity. This was not always

505 the case for STRUCTURE and DAPC results. This highlights the power of clustering

506 methods using a priori spatial information to infer complex population structure.

507 Indeed, although STRUCTURE was able to identify the same six clusters as TESS

508 when all samples were considered, it was unable to identify further fine-scale

509 structuring among coastal samples. Comparing the two approaches to infer the number

510 of clusters using STRUCTURE, supports the idea that Evanno's method is well

511 adapted to identify the first level of structuring under hierarchical scenarios (Waples

512 \& Gaggiotti 2006) such as those observed in bottlenose dolphins. DAPC also supports

513 the subdivision of bottlenose dolphins into six management units but assignment of

514 individuals to populations was less consistent with those of the two other methods. In

515 particular, one of the genetic clusters was composed of individuals sampled from many

516 different geographic locations. As Jombart et al. (2010) indicate, DAPC uses a purely

517 statistical criterion aimed at identifying the minimum number of groups that best

518 explain total observed variation while at the same time maximising between group

519 variation. Thus, as opposed to TESS and STRUCTURE, it does not take into

520 consideration Hardy-Weinberg and linkage equilibrium, which explains the observed

521 differences with the two other methods in the individual assignments to populations.

522 The use of stranded animals could be considered as a limitation of this study. However,

523 we are relatively confident in the inferences made, even though strandings constitute

524 almost half of all samples. Firstly, a drift-prediction model (Peltier et al., 2012) was

525 applied in a previous study (Louis, Viricel et al., 2014), to estimate the most likely area

526 of death. The estimated origin with the drift prediction model was consistent with the

527 genetic results separating coastal and pelagic bottlenose dolphins (Louis, Viricel et al., 
528 2014). For example, in East Scotland, all individuals were estimated to have died very

529 close to shore. The coastal and pelagic assignments of a subset of the samples were

530 confirmed using stable isotopes (Louis, Fontaine et al._.2014). In addition, 15 stranded

531 animals were known to be part of the resident coastal populations and their genetic

532 assignments matched photo-identification studies (Louis, Viricel et al., 2014).

533 Nevertheless, we acknowledge that there is uncertainty in the origin of the stranded

534 animals when there is no further evidence such as photo-identification and drift

535 modelling. This is the case for the coastal populations of Galicia and Wales/West

536 Scotland and caution is therefore required when interpreting these results.

537 The fine-scale population structure likely results from natal philopatry, possibly driven 538 by vertically (mother to offspring) and horizontally (between non-filial conspecifics)

539 learned foraging behaviours during the juvenile life stage, site fidelity and social 540 structure (Foote_et_al___2016;_Kopps _et_al.,2014; 541 discussion in Louis, Viricel et al., 2014; Louis, Fontaine et al., 2014; Nykänen et al., 542 2018). Photo-identification studies indicated site fidelity to relatively restricted 543 geographical areas (Cheney et al., 2014; Ingram \& Rogan, 2002; Louis et al., 2015), 544 however, individuals can undertake movements of a few hundreds of kilometres, i.e., 545 around Ireland (O'Brien et al., 2009) and the East coast of Scotland (Cheney et al., 546 2013) but these movements can still be considered occurring at a relatively small scale.

547 There is also some evidence of larger scale movements between the North Sea and the 548 Atlantic, as reported in Robinson et al. (2012), and this provides further potential for 549 genetic and demographic connectivity between the populations; seven transient 550 dolphins were first sighted in the Moray Firth, East Scotland and later re-sighted in the 551 Hebrides, West Scotland. Five of these animals were later recorded in coastal Irish 
552 waters and some of these movements represent travelled distances of over $1200 \mathrm{~km}$

553 (Robinson et al., 2012). These individuals are believed to be part of the West Ireland

554 population based on photo-identification catalogue kept on the coastal Irish dolphins.

555 However, photo-identification fieldwork mainly occurs during the summer in most

556 areas. Therefore, movements outside this season may be overlooked.

557 Despite the above-mentioned movements, our results are consistent with a very low

558 degree of connectivity among the studied populations. In other words, the different

559 populations are relatively isolated from each other. Estimated migration rates among

560 populations were very low, and less than $1 \%$ per generation for most of the pairwise

561 comparisons. Although there is no consensus on the level of migration that leads to

562 demographic coupling (Waples \& Gaggiotti, 2006; Palsboll et al., 2007), the estimated

563 migration rates are well below the rate of $10 \%$, which according to a simulation study

564 can lead to coupled dynamics (Hastings, 1993). Demographic connectivity is therefore

565 very low among local populations. The only exceptions are the migration rates of $18 \%$

566 from East Scotland to Galicia and 26\% from East Scotland to Wales, the latter of which

567 could be explained by the relatively short distance between the two sites. However, as

568 these populations included only stranded dolphins and although all the East Scotland

569 samples were estimated to originate from the North Sea according to a drift-prediction

570 model used in a previous study (Louis, Viricel et al., 2014), there is some uncertainty

571 about the origin of the individuals sampled in Wales and Galicia. As migration rate

572 estimates have been shown to be dependent on the number of clusters chosen to best

573 represent the population structure and thus the number of individuals in each cluster

574 (Olsen et al., 2014), great care has to be taken that the sampling strategy used is robust

575 and the samples are representative of each population. The present study is based on 
576 the most comprehensive set of genetic samples available but there is still a need for

577 more biopsy samples from Wales and Scotland to further support our results.

579 The different populations were characterised in terms of genetic diversity, 580 differentiation and migration rates. This information and existing estimates of 581 abundance will help to evaluate the conservation status and vulnerability of the 582 populations. Indeed, small isolated population are at risk of losing heterozygosity and 583 genetic resilience due to genetic drift (Lacy, 1987) and are thus more vulnerable to 584 stochastic environmental changes or anthropogenic stressors than larger populations. 585 Genetic diversity was higher in the pelagic populations than coastal populations as in 586 previous studies (Hoelzel et al., 1998; Louis, Viricel et al., 2014). This is consistent 587 with higher abundance of the pelagic populations compared to the coastal populations.

588 The Gibraltar-Cadiz population included around 700 photo-identified individuals 589 (Giménez et al., 2018) and the Pelagic Atlantic abundance estimates (from Scotland to 590 Spain) are several tens of thousands of individuals (Hammond et al., 2013, 2009) while 591 the abundances of coastal dolphins do not exceed $\sim 400$ individuals (see below).

592 Genetic diversity indices for the coastal populations were concordant with abundance 593 estimates using mark-recapture methods. The population of the English Channel, 594 which is the largest coastal population with abundance estimates of around 400 595 individuals (Louis et al., 2015), had the highest genetic diversity. The Shannon 596 population had the lowest genetic diversity and is the smallest with abundance 597 estimated between 110 and 140 dolphins (Berrow, 2012; Englund, Ingram, \& Rogan, 598 2008; Ingram \& Rogan, 2002, 2003; Rogan, Gkarakouni, Nykänen, Whitaker, \& 599 Ingram, 2018). Abundance estimates were around 200 individuals in East Scotland 
600 (Cheney et al., 2013), ca. 190 for the West Irish population (Nykänen, 2016) and 150 601 to 250 individuals in Wales (Pesante, Evans, Baines, \& McMath, 2008). Any local 602 perturbation or global change could thus have drastic negative effects on these coastal 603 populations due to their small size, low genetic diversity and low connectivity 604 uncovered in this study.

605 This study filled a major knowledge gap on the fine-scale population structure of 606 bottlenose dolphins in European Atlantic waters, which was considered as the main 607 research priority for the protection of this species (Ó Cadhla \& Marnell, 2017). As 608 previously found in Louis, Viricel et al. (2014), coastal and pelagic populations are 609 distinct and should be monitored separately. In terms of the coastal populations, the 610 high genetic differentiation and negligible migration rates found in this study highlight 611 the need to separately monitor each local population (the English Channel, the 612 Shannon, the West Ireland, the East Scotland, the Galicia and the Wales-West 613 Scotland populations) as they correspond to different management units. However, we 614 cannot rule out further fine-scale population division in Wales and West Scotland due 615 to the small sample sizes $(\mathrm{N}=16$ and $\mathrm{N}=5$, respectively), and the fact that all came from 616 stranded dolphins as the use of samples of stranded animals only may lead to under617 estimated population structure (Bilgmann, Möller, Harcourt, Kemper, \& Beheregaray, 618 2011)

619 The small population sizes of the coastal populations and their isolation may render 620 them vulnerable to anthropogenic impacts. These results highlight the need to protect 621 their habitat through protected areas such as the SACs where anthropogenic activities 622 are appropriately managed, ensuring their ecological suitability to the populations 623 utilizing them. Regular monitoring of population dynamics (e.g., abundance, survival, 
624 calving rate) using photo-identification, as undertaken in some of the areas, is therefore

625 recommended to evaluate population trends. Population viability analyses, as applied

626 to harbour seals, Phoca vitulina, in Southern Scandinavia in Olsen et al. (2014), could

627 also help inform whether the populations are of sufficient size for long-term population

628 viability in the absence of immigration.

629 In this study, management units were identified by first clustering individuals into

630 putative populations based on individuals' genotypes and then by estimating their

631 connectivity. Populations not sampled in this study (i.e., the Sado Estuary, Portugal,

632 and the Iroise Sea, France) could be genotyped in the future using the same set of

633 markers as in this study to further clarify their connectivity with the other European

634 Atlantic populations. The Atlantic pelagic population showed no genetic

635 differentiation over a large geographical range from West Scotland to the Azores.

636 However, pelagic bottlenose dolphin populations may show ecological differences

637 even in the absence of genetic divergence and this should be considered when

638 allocating management units. For example, the bottlenose dolphins of the Gibraltar

639 Strait and of the Gulf of Cadiz, although potentially presenting no genetic structure,

640 showed differences in ecology detected using different ecological tracers (i.e., stable

641 isotopes and contaminant loads) and individual monitoring through photo-

642 identification, leading to the delineation of two ecological, management units

643 (Giménez et al., 2018). This type of ecological differentiation may be detected using

644 next generation sequencing data covering the whole genome of the species, which

645 would allow testing for adaptive differentiation (Funk, McKay, Hohenlohe, \&

646 Allendorf, 2012). We recommend combining genetic data with ecological data (e.g.,

647 the use of stable isotopes) and individual monitoring, where available, to determine 
648 the geographical scales most relevant to monitoring and the protection of populations

649 of any species.

650

651 Data accessibility: The data are available on dryad at the following link: (to be

652 uploaded at the revisions stage).

654 Acknowledgments

655 We thank Andrew Foote for advice and comments, Amélia Viricel, Hélène Peltier

656 and Christophe Guinet for their help during ML's PhD study. We also thank

657 everyone involved in data collection: Conor Ryan (GMIT, IWDG), Nigel Monaghan

658 and Ruth Carden (National Museum of Ireland), Barry McGovern (SAC Inverness)

659 and Julie Béesau, Gill Murray-Dickson and Paul Thompson (University of

660 Aberdeen), GECC and Réseau National Echouages volunteers, Fabien Demaret,

661 Ghislain Doremus, Vincent Ridoux and Olivier Van Canneyt (Pelagis), Sami Hassani

662 (Océanopolis), Angela Llavona, Ruth Fernandez (CEMMA) and Paula Mendez-

663 Fernandez (CEMMA and LIENSs), Philippe Verborgh and Ruth Esteban (CIRCE),

664 Joan Giménez (EBD-CSIC) and all volunteers involved in sample collection from all

665 the organisations. All samples were taken under the relevant permits. UK samples

666 were collected under the aegis of the UK Cetacean Strandings Investigation

667 Programme, which is funded by Defra and the Devolved Administrations of Scotland

668 and Wales. Data from offshore Irish waters were collected on the Cetaceans on the

669 Frontier cruise thanks to National Marine Research Vessels Ship-Time Grant Aid

670 Programme 2010 funded under the Science Technology and Innovation Programme

671 of National Development Plan 2007-2013. Biopsy samples taken in Ireland were

672 carried out under licence from the National Parks and Wildlife Service (NPWS) Nos.

673 C104/2011 and DER/Dolphin2012-10 (licence numbers C111/2013 and C043/2014)

674 and the Health Products Regulatory Authority (licence number: AE19130/P014),

675 with biopsy sampling funded by the NPWS and by a grant to ER from Science

676 Foundation Ireland. Samples from Galicia were obtained with the support of

677 Dirección Xeral de Conservación da Natureza-Xunta de Galicia, cofinanced with 
678 European Regional Development Funds (ERDF/FEDER). Southern Spain samples

679 were collected thanks to LIFE 'Conservación de Cetáceos y tortugas de Murcia y 680 Andalucía' (LIFE 02 NAT/E/8610). MAS was supported by an FCT postdoctoral 681 grant (SFRH/BPD/29841/2006). Data collection in the Azores was funded by 682 projects TRACE (PTDC/MAR/74071/2006) and MAPCET (M2.1.2/F/012/2011). 683 Funding for sample collection in France and analyses was provided by Fondation 684 Total, Agence de l'Eau Seine-Normandie, Fonds de Dotation pour la Biodiversité, 685 Agence des Aires Marines Protégées, Association Nationale de la Recherche et de la 686 Technologie, Direction Régionale de l'Environnement, de l'Aménagement et du 687 Logement, Ministère de l'Ecologie, du Développement Durable et de l'Energie and 688 Conseil Général de la Manche. ML was supported by a Fyssen post-doctoral 689 fellowship, Fondation Total, a bridge funding from the School of Biology of the 690 University of St Andrews and People's Trust for Endangered Species. MN was 691 supported by NPWS, the Crawford-Hayes Fund, MASTS (Marine Alliance for 692 Science and Technology for Scotland) and Project FishKosm that is funded by the 693 Department of Agriculture, Food and the Marine's Competitive Research Funding 694 programmes. We would also like to thank the editors, Morten Tange Olsen and two 695 unnamed reviewers for helpful comments, which helped improve this manuscript.

\section{References}

698 Agardy, T., di Sciara, G. N., \& Christie, P. (2011). Mind the gap: Addressing the shortcomings of marine protected areas through large scale marine spatial planning. Marine Policy, 35(2), 226-232.

Allen, S. J., Bryant, K. A., Kraus, R. H. S., Loneragan, N. R., Kopps, A. M., Brown, 703 A. M., ... Krützen, M. (2016). Genetic isolation between coastal and fishery704 impacted, offshore bottlenose dolphin (Tursiops spp.) populations. Molecular 705 Ecology, 25(12), 2735-2753. https://doi.org/10.1111/mec.13622 
706 Allendorf, F. W., Luikart, G., \& Aitken, S. N. (2013). Conservation and the genetics of populations (2nd ed). Hoboken: John Wiley \& Sons.

708 Anderson, E. C., \& Dunham, K. K. (2008). The influence of family groups on inferences made with the program STRUCTURE. Molecular Ecology Resources, 8(6), 1219-1229. https://doi.org/10.1111/j.17550998.2008.02355.x

712 Anon. (2012). Notice of intention to designate The West Connacht Coast SAC (Site 713 code: 002998) as Special Area of Conservation. Department of Arts, Heritage and the Gaeltacht, Ireland. http://www.nwwac.org/ fileupload/Image/Description Sites Marine SACs Ireland_Dec2012_EN.pdf [July 27 2018]

717 Berrow, S. (2012). Abundance Estimate of Bottlenose Dolphins (Tursiops truncatus) 718 in the Lower River Shannon candidate Special Area of Conservation, Ireland. 719 Aquatic Mammals, 38(2), 136-144. https://doi.org/10.1578/AM.38.2.2012.136

721 Bilgmann, K., Möller, L. M., Harcourt, R. G., Kemper, C. M., \& Beheregaray, L. B. (2011). The use of carcasses for the analysis of cetacean population genetic structure: a comparative study in two dolphin species. Plos One, 6(5), e20103. https://doi.org/e20103 10.1371/journal.pone.0020103

725 Cheney, B., Corkrey, R., Durban, J. W., Grellier, K., Hammond, P. S., Islas726 Villanueva, V., ... Thompson, P. M. (2014). Long-term trends in the use of a 727 protected area by small cetaceans in relation to changes in population status. Global Ecology and Conservation, 2, 118-128. 
729

730

731

732

733

734

735

736

737

738

739

740

741

742

743

744

745

746

747

748

749

750

Cheney, B., Thompson, P. M., Ingram, S. N., Hammond, P. S., Stevick, P. T., Durban, J. W., ... Wilson, B. (2013). Integrating multiple data sources to assess the distribution and abundance of bottlenose dolphins Tursiops truncatus in Scottish waters: Abundance of bottlenose dolphins around Scotland. Mammal Review, 43(1), 71-88. https://doi.org/10.1111/j.13652907.2011.00208.x

Connor, R. C., Wells, R. S., Mann, J., \& Read, A. J. (2000). The bottlenose dolphin: social relationships in a fission-fusion society. In J. Mann, R. C. Connor, P.

L. Tyack, \& H. Whitehead (Eds.), Cetacean societies: field studies of dolphins and whales. (pp. 91-126). London, United Kingdom: The University of Chicago Press.

Council of the European Communities (2008). Directive 2008/56/EC of the European Parliament and of the Council of 17 June 2008 establishing a framework for community action in the field of marine environmental policy (Marine Strategy Framework Directive). Official Journal (L164), pp. 19-40.

Durand, E., Chen, E., \& Francois, O. (2009). Tess version 2.3 - Reference Manual.

Englund, A., Ingram, S. N., \& Rogan, E. (2008). An updated population status report for bottlenose dolphins using the Lower River Shannon SAC in 2008. Final Report to the National Parks and Wildlife Service (p. 34). University College Cork, Ireland.

European Commission (Ed.) (2011). The EU biodiversity strategy to 2020. Luxembourg: Publ. Off. of the Europ. Union. 
751 European Economic Community (1992). Council Directive 92/43/EEC of 21st May 1992 on the conservation of natural habitats and of wild fauna and flora.

Evanno, G., Regnaut, S., \& Goudet, J. (2005). Detecting the number of clusters of Official Journal (L206), pp. 7-50. individuals using the software STRUCTURE: a simulation study. Molecular Ecology, 14(8), 2611-2620. https://doi.org/10.1111/j.1365294X.2005.02553.X

Fernandez, R., Santos, M. B., Pierce, G. J., Llavona, A., Lopez, A., Silva, M. A., ... Piertney, S. B. (2011). Fine-scale genetic structure of bottlenose dolphins, Tursiops truncatus, in Atlantic coastal waters of the Iberian Peninsula. Hydrobiologia, 670(1), 111-125. https://doi.org/10.1007/s10750-011-0669-5

Foote, A. D., Vijay, N., Ávila-Arcos, M. C., Baird, R. W., Durban, J. W., Fumagalli, M., ... Wolf, J. B. W. (2016). Genome-culture coevolution promotes rapid divergence of killer whale ecotypes. Nature Communications, 7(1). https://doi.org/10.1038/ncomms 11693

Francis, R. M. (2017). pophelper: An R package and web app to analyse and visualise population structure. Molecular Ecology Resources, 17(1), 27-32. https://doi.org/10.1111/1755-0998.12509

Funk, W. C., McKay, J. K., Hohenlohe, P. A., \& Allendorf, F. W. (2012). Harnessing genomics for delineating conservation units. Trends in Ecology \& Evolution, 27(9), 489-496. https://doi.org/10.1016/j.tree.2012.05.012

Gaspari, S., Holcer, D., Mackelworth, P., Fortuna, C., Frantzis, A., Genov, T., ... Ciofi, C. (2015). Population genetic structure of common bottlenose dolphins (Tursiops truncatus) in the Adriatic Sea and contiguous regions: implications 
775

776

777

778

779

780

781

782

783

784

785

786

787

788

789

790

791

792

793

794

795

796

797

798

for international conservation. Aquatic Conservation: Marine and Freshwater Ecosystems, 25(2), 212-222. https://doi.org/10.1002/aqc.2415

Giménez, J., Louis, M., Barón, E., Ramírez, F., Verborgh, P., Gauffier, P., ... de Stephanis, R. (2018). Towards the identification of ecological management units: A multidisciplinary approach for the effective management of bottlenose dolphins in the southern Iberian Peninsula. Aquatic Conservation: Marine and Freshwater Ecosystems, 28(1), 205-215. https://doi.org/10.1002/aqc.2814

Glaubitz, J. C. (2004). CONVERT: A user-friendly program to reformat diploid genotypic data for commonly used population genetic software packages. Molecular Ecology Notes, 4(2), 309-310. https://doi.org/10.1111/j.14718286.2004.00597.x

Guillot, G., Leblois, R., Coulon, A., \& Frantz, A. C. (2009). Statistical methods in spatial genetics. Molecular Ecology, 18(23), 4734-4756. https://doi.org/10.1111/j.1365-294X.2009.04410.x

Hammond, P. S., Bearzi, G., Bjørge, A., Forney, K. A., Karczmarski, L., Kasuya, T., ... Wilson, B. (2012). Tursiops truncatus. The IUCN Red List of Threatened Species 2012: e.T22563A17347397. http://dx.doi.org/10.2305/IUCN.UK.2012.RLTS.T22563A17347397.en. [21 July 2018].

Hammond, P. S., Macleod, K., Berggren, P., Borchers, D. L., Burt, L., Cañadas, A., ... Vázquez, J. A. (2013). Cetacean abundance and distribution in European Atlantic shelf waters to inform conservation and management. Biological Conservation, 64, 107-122. 
799 Hammond, P. S., Macleod, K., Gillespie, D., Swift, R., Winship, A., Burt, M. L., ... 800 Castro, R. (2009). Cetacean Offshore Distribution and Abundance in the 801 European Atlantic (CODA). Final report to the European Commission. St $802 \quad$ Andrews.

803 Hartel, E. F., Constantine, R., \& Torres, L. G. (2015). Changes in habitat use patterns 804 by bottlenose dolphins over a 10-year period render static management boundaries ineffective: Changes in habitat use render management

808 Hastings, A. (1993). Complex interactions between dispersal and dynamics - lessons 809 from couple logistic equations. Ecology, 74(5), 1362-1372.

$810 \quad$ https://doi.org/10.2307/1940066

811 Hoelzel, A. R., Potter, C. W., \& Best, P. B. (1998). Genetic differentiation between parapatric 'nearshore'and 'offshore'populations of the bottlenose dolphin.

815 Hooker, S. K., \& Gerber, L. R. (2004). Marine reserves as a tool for ecosystem-based 816 management: the potential importance of megafauna. Bioscience, 54(1), 2739. Retrieved from http://bioscience.oxfordjournals.org/content/54/1/27.short

818 Ingram, S. N., Englund, A., \& Rogan, E. (2001). An extensive survey of bottlenose 819 dolphins (Tursiops truncatus) on the west coast of Ireland. Heritage Council 820 Report no. WLD/2001/42. (p. 17). University College Cork, Ireland.

821 Ingram, S. N., \& Rogan, E. (2002). Identifying critical areas and habitat preferences 822 of bottlenose dolphins Tursiops truncatus. Marine Ecology Progress Series, 
244, 247-255. Retrieved from http://www.intres.com/abstracts/meps/v244/p247-255/

825 Ingram, S. N., \& Rogan, E. (2003). Bottlenose dolphins (Tursiops truncatus) in the Shannon Estuary and selected areas of the west-coast of Ireland. Report to the National Parks and Wildlife Service (p. 28). University College Cork,

$828 \quad$ Ireland.

829 Jakobsson, M., \& Rosenberg, N. A. (2007). CLUMPP: a cluster matching and 830 permutation program for dealing with label switching and multimodality in 831 analysis of population structure. Bioinformatics (Oxford, England), 23(14), 832 1801-1806. https://doi.org/10.1093/bioinformatics/btm233

833 Jepson, P. D., Deaville, R., Barber, J. L., Aguilar, À., Borrell, A., Murphy, S., ... 834 Law, R. J. (2016). PCB pollution continues to impact populations of orcas 835 and other dolphins in European waters. Scientific Reports, 6, 18573.

836 https://doi.org/10.1038/srep18573

837 Jombart, T. (2008). adegenet: a R package for the multivariate analysis of genetic 838 markers. Bioinformatics, 24, 1403-1405.

839 https://doi.org/10.1093/bioinformatics/btn129

840 Jombart, T. (2012). A tutorial for Discriminant Analysis of Principal Components $841 \quad$ (DAPC) using adegenet 1.3-4.

842 Jombart, T., Devillard, S., \& Balloux, F. (2010). Discriminant analysis of principal 843 components: a new method for the analysis of genetically structured 844 populations. Bmc Genetics, 11, 94. https://doi.org/9410.1186/1471-2156-11845 94 
846 Jost, L. (2008). $G_{\mathrm{ST}}$ and its relatives do not measure differentiation. Molecular Ecology, 17(18), 4015-4026. https://doi.org/10.1111/j.1365294X.2008.03887.x

Keenan, K., McGinnity, P., Cross, T. F., Crozier, W. W., \& Prodöhl, P. A. (2013). diveRsity : An R package for the estimation and exploration of population genetics parameters and their associated errors. Methods in Ecology and Evolution, 4(8), 782-788. https://doi.org/10.1111/2041-210X.12067

Kelleher, G., \& Phillips, A. (Eds.). (1999). Guidelines For Marine Protected Areas. IUCN Publications Services Unit, 219c Huntingdon Road, Cambridge CB3 ODL, United Kingdom: IUCN, Gland, Switzerland and Cambridge, UK. https://doi.org/10.2305/IUCN.CH.1999.PAG.3.en

Kopps, A. M., Ackermann, C. Y., Sherwin, W. B., Allen, S. J., Bejder, L., \& Krutzen, M. (2014). Cultural transmission of tool use combined with habitat specializations leads to fine-scale genetic structure in bottlenose dolphins. Proceedings of the Royal Society B: Biological Sciences, 281(1782), 20133245-20133245. https://doi.org/10.1098/rspb.2013.3245

Lacy, R. C. (1987). Loss of Genetic Diversity from Managed Populations: Interacting Effects of Drift, Mutation, Immigration, Selection, and Population 
871 Louis, M., Gally, F., Barbraud, C., Béesau, J., Tixier, P., Simon-Bouhet, B., ...

872 Guinet, C. (2015). Social structure and abundance of coastal bottlenose

873 dolphins, Tursiops truncatus, in the Normano-Breton Gulf, English Channel.

$874 \quad$ Journal of Mammalogy, gyv053. Retrieved from

875 http://jmammal.oxfordjournals.org/content/early/2015/04/30/jmammal.gyv05

$876 \quad 3 . a b s t r a c t$

877 Louis, M., Viricel, A., Lucas, T., Peltier, H., Alfonsi, E., Berrow, S., ... Simon-

878 Bouhet, B. (2014). Habitat-driven population structure of bottlenose dolphins,

879 Tursiops truncatus, in the North-East Atlantic. Molecular Ecology, 23(4),

$880 \quad$ 857-874. https://doi.org/10.1111/mec.12653

881 Lusseau, D., Bain, D., Williams, R., \& Smith, J. (2009). Vessel traffic disrupts the

882 foraging behavior of southern resident killer whales Orcinus orca.

883 Endangered Species Research, 6, 211-221. https://doi.org/10.3354/esr00154

884 Meissner, A. M., Christiansen, F., Martinez, E., Pawley, M. D. M., Orams, M. B., \&

885 Stockin, K. A. (2015). Behavioural Effects of Tourism on Oceanic Common

886 Dolphins, Delphinus sp., in New Zealand: The Effects of Markov Analysis

887 Variations and Current Tour Operator Compliance with Regulations. PLOS

$888 \quad O N E, 10(1)$, e0116962. https://doi.org/10.1371/journal.pone.0116962

889 Mirimin, L., Miller, R., Dillane, E., Berrow, S. D., Ingram, S., Cross, T. F., \& Rogan,

890 E. (2011). Fine-scale population genetic structuring of bottlenose dolphins in

891 Irish coastal waters: Population genetic structure of bottlenose dolphins.

892 Animal Conservation, 14(4), 342-353. https://doi.org/10.1111/j.1469-

$893 \quad 1795.2010 .00432 . x$ 
894 Moritz, C. (1994). Defining evolutionarily significant units for conservation. Trends 895 in Ecology \& Evolution, 9(10), 373-375. https://doi.org/10.1016/0169-

Natoli, A., Peddemors, V. M., \& Hoelzel, A. R. (2003). Population structure and speciation in the genus Tursiops based on microsatellite and mitochondrial DNA analyses: Bottlenose dolphin population genetics. Journal of Evolutionary Biology, 17(2), 363-375. https://doi.org/10.1046/j.1420-

914 O’Brien, J., Berrow, S., Ryan, C., McGrath, D., O’Connor, I., Giovanna, P., ...

915 Whooley, P. (2009). A note on long-distance matches of bottlenose dolphins

916 (Tursiops truncatus) around the Irish coast using photo-identification. from https://cual.openrepository.com/cual/handle/10759/347018 
919 Ó Cadhla, O., \& Marnell, F. (Eds.) (2017). Proceedings of the Transnational

920 Bottlenose Dolphin Conservation Workshop hosted in Dublin, 7-8 December

921 2016. National Parks \& Wildlife Service, Department of Arts, Heritage,

922 Regional, Rural and Gaeltacht Affairs, Dublin, Ireland. 391pp.

923 Olsen, M. T., Andersen, L. W., Dietz, R., Teilmann, J., Harkonen, T., \& Siegismund,

924 H. R. (2014). Integrating genetic data and population viability analyses for

925 the identification of harbour seal (Phoca vitulina) populations and

926 management units. Molecular Ecology, 23(4), 815-831.

927 https://doi.org/10.1111/mec. 12644

928 Palsbøll, P. J., Berube, M., \& Allendorf, F. W. (2007). Identification of management

929 units using population genetic data. Trends in Ecology \& Evolution, 22(1),

$930 \quad 11-16$. https://doi.org/10.1016/j.tree.2006.09.003

931 Peltier, H., Dabin, W., Daniel, P., Van Canneyt, O., Dorémus, G., Huon, M., \&

932 Ridoux, V. (2012). The significance of stranding data as indicators of

933 cetacean populations at sea: Modelling the drift of cetacean carcasses.

934 Ecological Indicators, 18, 278-290.

$935 \quad$ https://doi.org/10.1016/j.ecolind.2011.11.014

936 Pesante, G., Evans, P. G. H., Baines, M. E., \& McMath, M. (2008). Abundance and

937 life history parameters of bottlenose dolphin in Cardigan Bay: monitoring

938 2005-2007. CCW Marine Monitoring Report.

939 Pirotta, E., Merchant, N. D., Thompson, P. M., Barton, T. R., \& Lusseau, D. (2015).

940 Quantifying the effect of boat disturbance on bottlenose dolphin foraging

$941 \quad$ activity. Biological Conservation, 181, 82-89.

942 https://doi.org/10.1016/j.biocon.2014.11.003 
943 Pritchard, J. K., Stephens, M., \& Donnelly, P. (2000). Inference of population structure using multilocus genotype data. Genetics, 155(2), 945-959.

945 Queller, D. C., \& Goodnight, K. F. (1989). Estimating relatedness using genetic

946 markers. Evolution, 43(2), 258-275. https://doi.org/10.2307/2409206

947 Quérouil, S., Silva, M. A., Freitas, L., Prieto, R., Magalhães, S., Dinis, A., ... Santos,

948 R. S. (2007). High gene flow in oceanic bottlenose dolphins (Tursiops

949 truncatus) of the North Atlantic. Conservation Genetics, 8(6), 1405-1419.

$950 \quad$ https://doi.org/10.1007/s10592-007-9291-5

951 Quick, N. J., Cheney, B., Islas-Villanueva, V., Janik, V. M., Thompson, P. M., \&

$952 \quad$ Hammond, P. S. (2014). The east coast of Scotland bottlenose dolphin

953 population: Improving understanding of ecology outside the Moray Firth

954 SAC. Report produced as part of the UK Department of Energy and Climate

$955 \quad$ Change's offshore energy Strategic Environmental Assessment programme

956 (OESEA2 Supporting documents No. 14D-086) (p. 87). Department of

957 Energy and Climate Change. Retrieved from

958 https://www.gov.uk/government/uploads/system/uploads/attachment_data/fil

959 e/346326/OESEA2_east_coast_of_Scotland_bottlenose_dolphin_population.

$960 \quad$ pdf

961 Rambaut, A., \& Drummond, A. J. (2007). Tracer v1.4, Available from

962 http://beast.bio.ed.ac.uk/Tracer.

963 Rannala, B. (2013). BayesAss Edition 3.0 User's Manual. University of California

964 Davis.

965 Raymond, M., \& Rousset, F. (1995). GENEPOP (version 1.2) - Population genetics

966 software for exact tests and ecumenicism. Journal of Heredity, 86(3), 248-

967249 
968 R Core Team (2018). R: A language and environment for statistical computing. R 969

970 Foundation for Statistical Computing, Vienna, Austria. https://www.R-

Reif, J., Schaefer, A., Bossart, G., \& Fair, P. (2017). Health and Environmental Risk Assessment Project for bottlenose dolphins Tursiops truncatus from the southeastern USA. II. Environmental aspects. Diseases of Aquatic Organisms, 125(2), 155-166. https://doi.org/10.3354/dao03143

975 Robinson, K. P., O’Brien, J., Berrow, S., Cheney, B., Costa, M., Elsfield, S. M., ...

976 Whooley, P. (2012). Discrete or not so discrete: Long distance movements by 977 coastal bottlenose dolphins in UK and Irish waters. Journal of Cetacean

$978 \quad$ Research and Management, 12(3), 365-371. Retrieved from

979 http://cual.openrepository.com/cual/handle/10759/560746

980 Rogan, E., Gkarakouni, M., Nykänen, M., Whitaker, A., \& Ingram, S. N. (2018).

981 Bottlenose dolphin survey in the Lower River Shannon SAC 2018. Report to

982 the National Parks and Wildlife Service, Department of Arts, Heritage,

983 Regional, Rural and Gaeltacht Affairs (p. 22). Cork: University College

$984 \quad$ Cork.

985 Rosel, P. E., Hansen, L., \& Hohn, A. A. (2009). Restricted dispersal in a

986 continuously distributed marine species: common bottlenose dolphins

987 Tursiops truncatus in coastal waters of the western North Atlantic. Molecular

988 Ecology, 18(24), 5030-5045. https://doi.org/10.1111/j.1365-

$989 \quad$ 294X.2009.04413.x 
990 Rousset, F. (2008). GENEPOP'007: a complete re-implementation of the GENEPOP 991

992 software for Windows and Linux. Molecular Ecology Resources, 8(1), 103-

993 106. https://doi.org/10.1111/j.1471-8286.2007.01931.x

Van Oosterhout, C., Hutchinson, W. F., Wills, D. P. M., \& Shipley, P. (2004). MICRO-CHECKER: software for identifying and correcting genotyping errors in microsatellite data. Molecular Ecology Notes, 4(3), 535-538. https://doi.org/10.1111/j.1471-8286.2004.00684.x

Vollmer, N. L., \& Rosel, P. E. (2017). Fine-scale population structure of common bottlenose dolphins (Tursiops truncatus) in offshore and coastal waters of the US Gulf of Mexico. Marine Biology, 164(8). https://doi.org/10.1007/s00227-

Wang, J. (2011). coancestry: a program for simulating, estimating and analysing relatedness and inbreeding coefficients: COMPUTER PROGRAM NOTE. Molecular Ecology Resources, 11(1), 141-145. https://doi.org/10.1111/j.1755-0998.2010.02885.x

Waples, R. S., \& Gaggiotti, O. (2006). What is a population? An empirical evaluation of some genetic methods for identifying the number of gene pools and their degree of connectivity. Molecular Ecology, 15(6), 1419-1439. https://doi.org/10.1111/j.1365-294X.2006.02890.x

Weir, B. S., \& Cockerham, C. C. (1984). Estimating F-statistics for the analysis of population structure. Evolution, 38(6), 1358-1370.

1012 Whitehead, H. (2017). Gene-culture coevolution in whales and dolphins. https://doi.org/10.1073/pnas.1620736114 
1015 Williams, R., Bain, D., Smith, J., \& Lusseau, D. (2009). Effects of vessels on 1016 behaviour patterns of individual southern resident killer whales Orcinus orca. Endangered Species Research, 6, 199-209. https://doi.org/10.3354/esr00150

1018 Wilson, B. (2016). Might marine protected areas for mobile megafauna suit their 1019 proponents more than the animals?: MPAs for megafauna or people? Aquatic $1020 \quad$ Conservation: Marine and Freshwater Ecosystems, 26(1), 3-8.

$1021 \quad$ https://doi.org/10.1002/aqc.2619

1022 Wilson, G. A., \& Rannala, B. (2003). Bayesian inference of recent migration rates 1023 using multilocus genotypes. Genetics, 163(3), 1177-1191.

1024

1025

1026

1027

1028

1029

1030

1031

1032

1033

1034

1035

1036

1037

1038

1039 
1040 Tables

1041

1042 Table 1. Pairwise fixation indices based on 14 microsatellite loci (given as average

1043 with 95\% Highest Probability Density Interval (HPDI)) between the different

1044 populations. The samples were divided into populations based on results from TESS.

1045 Values above the diagonal are $F_{\mathrm{ST}}$-values and values below the diagonal are Jost's $D$

1046 values.

\begin{tabular}{|c|c|c|c|c|c|c|c|c|}
\hline & $\begin{array}{c}\text { Shanno } \\
n\end{array}$ & $\begin{array}{c}\text { Wales/W } \\
\text { est } \\
\text { Scotland }\end{array}$ & $\begin{array}{c}\text { East } \\
\text { Scotlan } \\
\text { d }\end{array}$ & $\begin{array}{l}\text { West } \\
\text { Ireland }\end{array}$ & $\begin{array}{l}\text { English } \\
\text { Channel }\end{array}$ & Galicia & $\begin{array}{l}\text { Gibralta } \\
\text { r/Cadiz }\end{array}$ & $\begin{array}{l}\text { Pelagic } \\
\text { Atlantic }\end{array}$ \\
\hline Shannon & - & $\begin{array}{c}0.136 \\
(0.096- \\
0.180)\end{array}$ & $\begin{array}{c}0.164 \\
(0.130- \\
0.200)\end{array}$ & $\begin{array}{c}0.129 \\
(0.104- \\
0.153)\end{array}$ & $\begin{array}{c}0.090 \\
(0.079- \\
0.103)\end{array}$ & $\begin{array}{c}0.226 \\
(0.178- \\
0.283)\end{array}$ & $\begin{array}{c}0.232 \\
(0.215- \\
0.249)\end{array}$ & $\begin{array}{c}0.227 \\
(0.212- \\
0.241)\end{array}$ \\
\hline $\begin{array}{l}\text { Wales/W } \\
\text { est } \\
\text { Scotland }\end{array}$ & $\begin{array}{c}0.090 \\
(0.061- \\
0.121)\end{array}$ & - & $\begin{array}{c}0.066 \\
(0.037- \\
0.103)\end{array}$ & $\begin{array}{c}0.128 \\
(0.092- \\
0.169)\end{array}$ & $\begin{array}{c}0.082 \\
(0.058- \\
0.111)\end{array}$ & $\begin{array}{c}0.125 \\
(0.083- \\
0.176)\end{array}$ & $\begin{array}{c}0.173 \\
(0.154- \\
0.197)\end{array}$ & $\begin{array}{c}0.178 \\
(0.159- \\
0.198)\end{array}$ \\
\hline $\begin{array}{l}\text { East } \\
\text { Scotland }\end{array}$ & $\begin{array}{c}0.141 \\
(0.104- \\
0.176)\end{array}$ & $\begin{array}{c}0.036 \\
(0.010- \\
0.075)\end{array}$ & - & $\begin{array}{c}0.149 \\
(0.119- \\
0.183)\end{array}$ & $\begin{array}{c}0.090 \\
(0.067- \\
0.114)\end{array}$ & $\begin{array}{c}0.091 \\
(0.062- \\
0.131)\end{array}$ & $\begin{array}{c}0.150 \\
(0.129- \\
0.172)\end{array}$ & $\begin{array}{c}0.164 \\
(0.147- \\
0.183)\end{array}$ \\
\hline $\begin{array}{l}\text { West } \\
\text { Ireland }\end{array}$ & $\begin{array}{c}0.074 \\
(0.056- \\
0.095)\end{array}$ & $\begin{array}{c}0.089 \\
(0.064- \\
0.116)\end{array}$ & $\begin{array}{c}0.115 \\
(0.086- \\
0.148)\end{array}$ & - & $\begin{array}{c}0.115 \\
(0.099- \\
0.131)\end{array}$ & $\begin{array}{c}0.178 \\
(0.132- \\
0.234)\end{array}$ & $\begin{array}{c}0.208 \\
(0.190- \\
0.227)\end{array}$ & $\begin{array}{c}0.190 \\
(0.177- \\
0.206)\end{array}$ \\
\hline $\begin{array}{l}\text { English } \\
\text { Channel }\end{array}$ & $\begin{array}{c}0.065 \\
(0.052- \\
0.079)\end{array}$ & $\begin{array}{c}0.082 \\
(0.054- \\
0.115)\end{array}$ & $\begin{array}{c}0.081 \\
(0.054- \\
0.110)\end{array}$ & $\begin{array}{c}0.104 \\
(0.085- \\
0.125)\end{array}$ & & $\begin{array}{c}0.094 \\
(0.065- \\
0.134)\end{array}$ & $\begin{array}{c}0.134 \\
(0.122- \\
0.146)\end{array}$ & $\begin{array}{c}0.146 \\
(0.136- \\
0.157)\end{array}$ \\
\hline Galicia & $\begin{array}{c}0.174 \\
(0.123- \\
0.234)\end{array}$ & $\begin{array}{c}0.098 \\
(0.042- \\
0.164)\end{array}$ & $\begin{array}{c}0.054 \\
(0.027- \\
0.090)\end{array}$ & $\begin{array}{c}0.111 \\
(0.067- \\
0.164)\end{array}$ & $\begin{array}{c}0.093 \\
(0.060- \\
0.142)\end{array}$ & $P^{-}$ & $\begin{array}{c}0.140 \\
(0.115- \\
0.173)\end{array}$ & $\begin{array}{c}0.139 \\
(0.116- \\
0.170)\end{array}$ \\
\hline $\begin{array}{l}\text { Gibraltar } \\
\text { /Cadiz }\end{array}$ & $\begin{array}{c}0.386 \\
(0.346- \\
0.426)\end{array}$ & $\begin{array}{c}0.289 \\
(0.246- \\
0.331)\end{array}$ & $\begin{array}{c}0.260 \\
(0.220- \\
0.310)\end{array}$ & $\begin{array}{c}0.347 \\
(0.308- \\
0.388)\end{array}$ & $\begin{array}{c}0.286 \\
(0.254- \\
0.320)\end{array}$ & $\begin{array}{c}0.259 \\
(0.214- \\
0.312)\end{array}$ & - & $\begin{array}{c}0.034 \\
(0.026- \\
0.043)\end{array}$ \\
\hline $\begin{array}{l}\text { Pelagic } \\
\text { Atlantic }\end{array}$ & $\begin{array}{c}0.457 \\
(0.423- \\
0.492)\end{array}$ & $\begin{array}{c}0.359 \\
(0.318- \\
0.398)\end{array}$ & $\begin{array}{c}0.345 \\
(0.310- \\
0.384)\end{array}$ & $\begin{array}{c}0.379 \\
(0.347- \\
0.414)\end{array}$ & $\begin{array}{c}0.351 \\
(0.324- \\
0.377)\end{array}$ & $\begin{array}{c}0.335 \\
(0.281- \\
0.401)\end{array}$ & $\begin{array}{c}0.097 \\
(0.072- \\
0.126)\end{array}$ & - \\
\hline
\end{tabular}


1048 Table 2. Nuclear diversities over all loci for each population inferred by TESS.

\begin{tabular}{|c|c|c|c|c|c|c|c|c|c|c|c|}
\hline Population & $\mathrm{N}$ (mean) & $A$ & $\%$ & AR & $\mathrm{Ho}$ & $\mathrm{He}$ & HWE & $F_{\text {IS }}$ & $F_{\text {IS Low }}$ & $F_{\text {IS }}$ High & PA \\
\hline Shannon & 52 & 52 & 31.19 & 3.06 & 0.44 & 0.42 & 0.997 & $-0.0604 *$ & -0.1215 & -0.0014 & 0 \\
\hline Wales/West Scotland & 20 & 57 & 35.86 & 3.36 & 0.46 & 0.48 & 0.839 & 0.0362 & -0.0744 & 0.1386 & 1 \\
\hline East Scotland & 31 & 54 & 35.94 & 3.42 & 0.52 & 0.54 & 0.982 & 0.0297 & -0.0565 & 0.1067 & 1 \\
\hline West Ireland & 36 & 53 & 34.82 & 3.30 & 0.51 & 0.47 & 1.000 & $-0.0754 *$ & -0.1358 & -0.0204 & 0 \\
\hline English Channel & 111 & 93 & 57.45 & 4.75 & 0.60 & 0.60 & 0.971 & 0.0115 & -0.0244 & 0.0470 & 2 \\
\hline Galicia & 13 & 58 & 36.90 & 3.76 & 0.60 & 0.55 & 0.419 & $-0.0892 *$ & -0.2011 & -0.0046 & 0 \\
\hline Gibraltar/Cadiz & 49 & 113 & 72.10 & 6.10 & 0.73 & 0.74 & 0.463 & 0.0141 & -0.0172 & 0.0462 & 2 \\
\hline Pelagic Atlantic & 106 & 148 & 92.43 & 7.07 & 0.75 & 0.77 & 0.998 & 0.0266 & 0.0030 & 0.0497 & 26 \\
\hline
\end{tabular}

$1049 \mathrm{~N}=$ mean number of individuals used for each locus, $\mathrm{A}=$ number of alleles observed, $\%=$ percentage of total alleles, $\mathrm{AR}=$ allelic richness,

$1050 H o=$ observed heterozygosity, $H e=$ expected heterozygosity, are given as per locus per population sample. Hardy-Weinberg Equilibrium

1051 (HWE) $=$ corrected p-values (chi-square test for goodness-of-fit), $F_{\text {IS }}=F_{\text {IS }}$ values for each loci and population sample (overall), $F_{\text {IS }}$ Low/High=bias

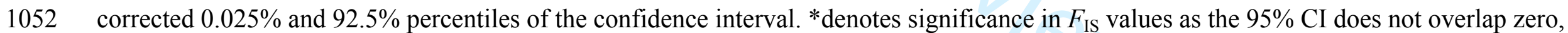

$1053 \quad \mathrm{PA}=$ number of Private Alleles. 
1055 Table 3. Mean (and 95\% Credible Interval) recent migration rates inferred using BayesAss. The migration rate is defined as the proportion of

1056 individuals in a population that immigrated from a source population per generation. Migration rates above 0.10 have been highlighted in bold.

10

\begin{tabular}{|c|c|c|}
\hline Ppppulation \Source & Shannon & Wales/West Scotlan \\
\hline IShannon & $0.959(0.931-0.987)$ & $0.005(0.000-0.016$ \\
\hline Wales/West-Scotland & $0.012(0.000-0.036)$ & $0.678(0.657-0.700$ \\
\hline EFast Scotland & $0.010(0.000-0.030)$ & $0.008(0.000-0.025$ \\
\hline NGest Ireland & $0.054(0.000-0.112)$ & $0.008(0.000-0.022$ \\
\hline English Channel & $0.008(0.000-0.021)$ & $0.003(0.000-0.008$ \\
\hline $\begin{array}{l}\text { 18alicia } \\
19\end{array}$ & $0.015(0.000-0.043)$ & $0.014(0.000-0.041$ \\
\hline $20 \mathrm{bbraltar} /$ Cadiz & $0.006(0.000-0.017)$ & $0.006(0.000-0.018$ \\
\hline Plelagic Atlantic & $0.003(0.000-0.009)$ & $0.003(0.000-0.00$ \\
\hline
\end{tabular}

East Scotland

0.007 (0.000 - 0.019) $0.006(0.000-0.018)$

$0.257(0.206-0.307) \quad 0.010(0.000-0.029)$

$0.935(0.892-0.978) \quad 0.009(0.000-0.027)$

$0.009(0.000-0.028) \quad 0.898(0.833-0.964)$

$0.007(0.000-0.019) \quad 0.005(0.000-0.013)$

$\mathbf{0 . 1 8 1}(\mathbf{0 . 1 0 4 - 0 . 2 5 7 )} \quad 0.015(0.000-0.043)$

$0.006(0.000-0.018) \quad 0.006(0.000-0.017)$

$0.003(0.000-0.009) \quad 0.003(0.000-0.009)$
English Channel Galicia

$0.006(0.000-0.018)$

$0.013(0.000-0.037)$

$0.011(0.000-0.030)$

$0.008(0.000-0.024)$

$0.969(0.948-0.990)$

$0.062(0.000-0.127)$

$0.006(0.000-0.018)$

$0.004(0.000-0.011)$
$0.005(0.000-0.016)$

$0.010(0.000-0.029)$

$0.009(0.000-0.025)$

$0.008(0.000-0.022)$

$0.003(0.000-0.008)$

$0.684(0.652-0.716)$

$0.006(0.000-0.017)$

$0.003(0.000-0.009)$
Gibraltar/Cadiz

$0.005(0.000-0.016)$

$0.010(0.000-0.029)$

$0.009(0.000-0.026)$

$0.008(0.000-0.022)$

$0.003(0.000-0.008)$

0.014 (0.000 - 0.041)

$0.941(0.902-0.981)$

$0.008(0.000-0.022)$ 


\section{Figure legends}

Figure 1. Map of samples used in the study and their origin; stranding - samples collected from stranded bottlenose dolphins, biopsy - samples collected from skin biopsies, and catalogued samples collected from stranded animals that had been matched to a photo-identification catalogue of known coastal dolphins. The grey contours represent $200 \mathrm{~m}$ and $1000 \mathrm{~m}$ depth contours.

Figure 2. Map of individual assignment probabilities per population identified by TESS using the whole dataset $(\mathrm{N}=425)$ and $K=6$. The color scale bar indicates the assignment probabilities, (a) East and West Scotland, Wales and Galicia, (b) West Ireland, (c) Shannon estuary, Ireland, (d) English Channel, France, (e) pelagic Atlantic, (f) Gibraltar-Cadiz.

Figure 3. Results of TESS analyses involving only coastal samples. A) Map of individual assignment probabilities per population using all coastal samples $(\mathrm{N}=269)$ and $K=5$ : (a) East Scotland and Wales (b) West Ireland, (c) Shannon estuary, Ireland, (d) English Channel, France, (e) Galicia, Spain. (B) Map of individual assignment probabilities per population using only the samples from coastal Wales, West and East Scotland ( $\mathrm{N}=53$ ) and $K=2$ : (a) West Scotland and Wales (b) East Scotland. The color scale bar indicates the assignment probabilities. 


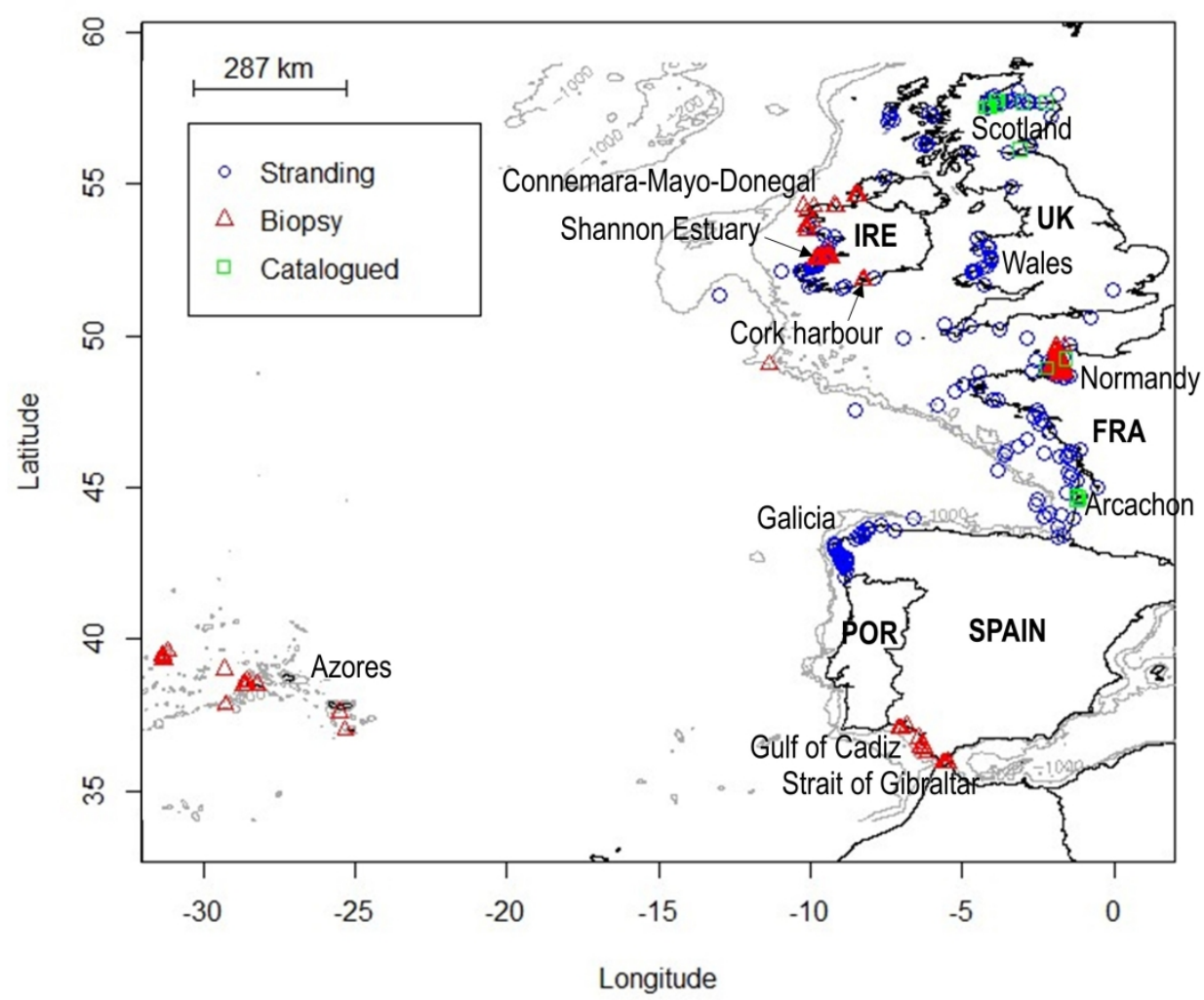

Figure 1. Map of samples used in the study and their origin; stranding - samples collected from stranded bottlenose dolphins, biopsy - samples collected from skin biopsies, and catalogued - samples collected from stranded animals that had been matched to a photo-identification catalogue of known coastal dolphins. The grey contours represent $200 \mathrm{~m}$ and $1000 \mathrm{~m}$ depth contours.

$208 \times 181 \mathrm{~mm}(300 \times 300$ DPI $)$ 


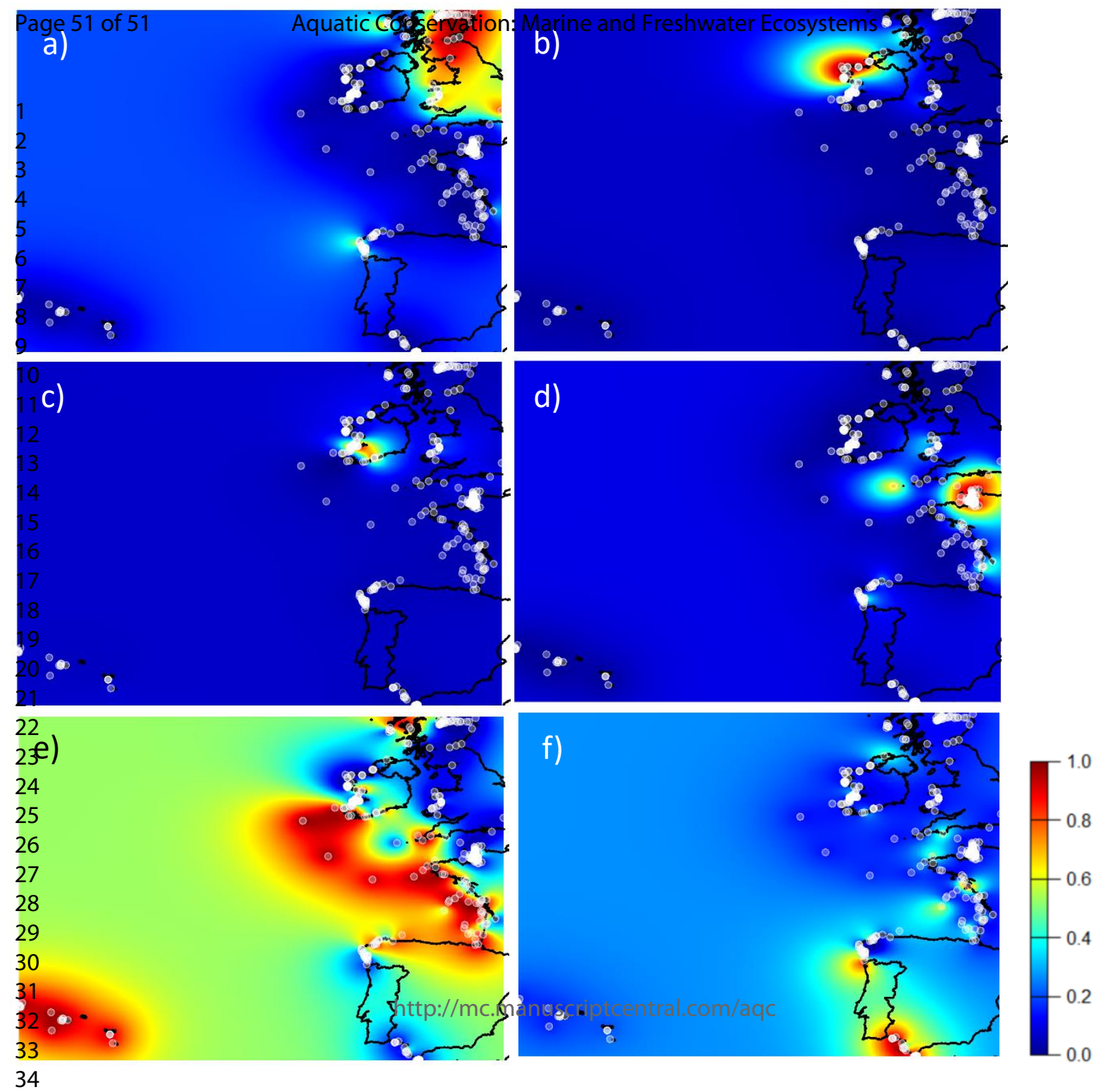


A) Coastal samples $-K=5$
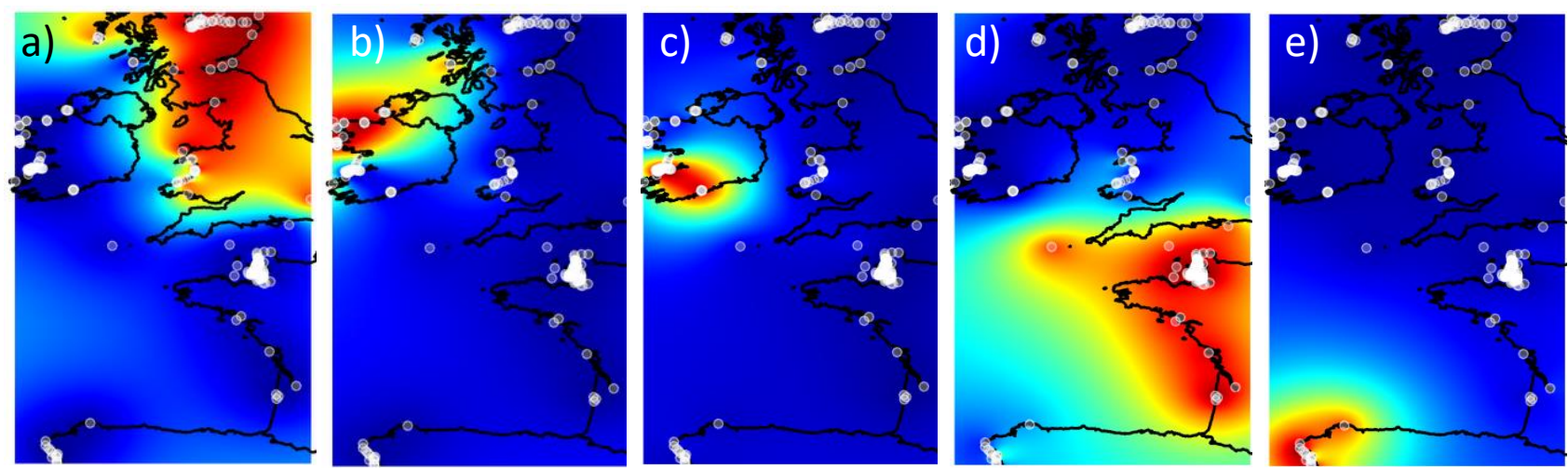

B) Wales and all Scotland coastal samples $-K=2$

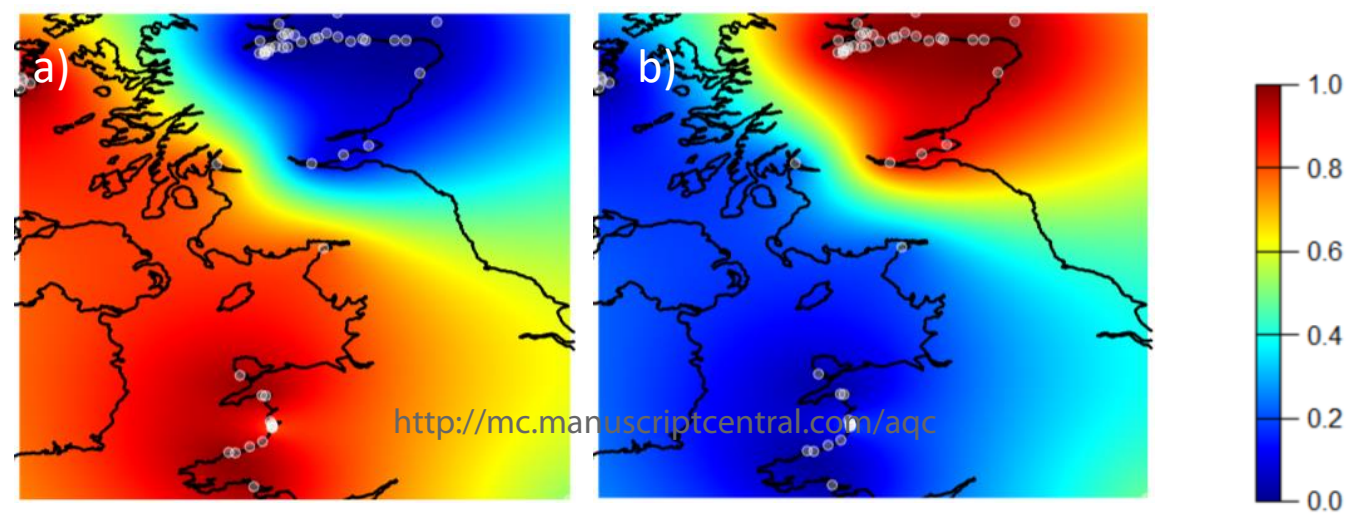

